\title{
Chelated aryllithium reagent: ortho- and para-pyrrolidinomethylphenyllithium
}

\author{
Hans J. Reich,* Wayne S. Goldenberg, and Aaron W. Sanders \\ Department of Chemistry, University of Wisconsin, Madison, Wisconsin 53706 \\ E-mail: reich@chem.wisc.edu
}

Dedicated to Karsten Krohn on the occasion of his $60^{\text {th }}$ birthday

(received 25 Sept 04; accepted 01 Dec 04; published on the web 21 Dec 04)

\begin{abstract}
Multinuclear NMR studies have been performed on two isomeric aryllithium reagents, one with an ortho amine chelating group (5-ring chelate, 4) and the second, a non-chelating model (5) with the same group in the para position. Both compounds were prepared isotopically enriched in ${ }^{6} \mathrm{Li}$ as solutions in THF or mixtures of THF with ethyl and/or methyl ether. Solution dynamics (aggregate interchange, chelation averaging) were measured by DNMR experiments. The model compound 5 is a mixture of dimer and monomer in $\operatorname{THF}\left(K_{\mathrm{MD}}=180 \mathrm{M}^{-1}\right)$. Several bidentate chelating cosolvents (TMEDA, dimethyl-2-methoxyethylamine and 2-dimethylaminomethyltetrahydrofuran) interacted with 5 to give mono and bis complexes of the dimers as well as mono-complexed monomer, with only minimal changes in the monomer to dimer ratio. Compound $\mathbf{4}$ in THF solution forms a strong dimer as a single chelation isomer of the B-type. The dynamics of decoordination of the pyrrolidine groups was measured by DNMR coalescence of the diastereotopic pyrrolidine ring carbons $\left(G^{\ddagger} 190=8.5 \mathrm{kcal} / \mathrm{mol}\right)$, and the dynamics of aggregate exchange were measured both by loss of C-Li coupling, and by exchange of 4 dimer with the mixed dimer $16\left(G_{246}^{*}=12.5-13.0 \mathrm{kcal} / \mathrm{mol}\right)$. Compound 4 interacts only very weakly with TMEDA, but HMPA causes significant conversion of dimer to monomer. The Li/I exchange of 4 and the analogous iodide 17 was slower by 5 orders of magnitude than the $\mathrm{PhLi} / \mathrm{PhI}$ exchange. A ${ }^{119} \mathrm{Sn}$ NMR study of a series of trimethylstannylaryl compounds with ortho substituents that could form a 5-membered chelate with an ether or amino group were weakly chelated.
\end{abstract}

Keywords: Chelated aryllithium, aggregate interchange, lithium-iodine exchange

\section{Introduction}

The detailed consideration of chelation effects in organolithium reagents began with the work of Hauser ${ }^{[1]}$ who recognized that the dimethylaminomethyl group could facilitate the metalation of ortho aryl hydrogens which otherwise could not be metalated (e.g., to form 2 from 1, Scheme 1). 
Numerous subsequent studies have involved many presumably chelated lithium and other organometallic reagents. $^{[2,3]}$

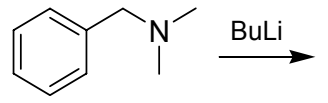

1

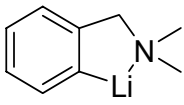

2

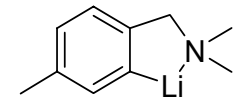

3

\section{Scheme 1}

The structural aspects of compound 2 and some of its analogs (both with other amine substituents as well as with a variety of metals) have been studied extensively. ${ }^{[4,5]}$ The X-Ray structure of crystals grown from ether-hexane showed 2 to be tetrameric, with each lithium vertex coordinated by a nitrogen. ${ }^{[4]}$ It resembles the structure of tetrameric $\mathrm{PhLi}^{[6]}$ except that the amino group replaces the coordinated ether molecule on each Li atom. Solution studies on the more soluble 3 showed that in toluene or diethyl ether the tetrameric structure and $N$ chelation remains intact, but addition of a small amount of THF (1 equiv) gave a dimeric structure as evidenced by $\mathrm{C}$-Li coupling and ${ }^{13} \mathrm{C}$ chemical shifts. Although there were indications that in THF the intramolecular N-Li coordination has been broken, subsequent investigations showed that the solution structure of 2 in THF showed strong chelation, with several chelation isomers present. ${ }^{[7 \mathrm{a}]}$ We report here a study of $\mathbf{4}$, the pyrrolidine analog of $\mathbf{2}$, and a model system 5 incapable of chelation.

\section{Results and Discussion}

Pyrrolidinomethylbenzene could not be metalated cleanly, so solutions of both $\mathbf{4}$ and $\mathbf{5}$ were prepared by $\mathrm{Li} / \mathrm{Sn}$ exchange of stannylated precursors 6 and 7. These were available as illustrated for 4 (Scheme 1) by reaction of $o$-bromobenzyl bromide (8) with pyrrolidine. The aryl bromides were not used directly to prepare lithium reagents for spectroscopic studies because of interference from $\mathrm{LiBr}$ (if $t$-BuLi was used) or bromobutane (if $n$ - or sec-BuLi was used). Both lithium reagents were prepared in ether by Li/Sn exchange (using 6 and 7), and the lithium reagent was purified by crystallization from diethyl or dimethyl ether before solutions were prepared for spectroscopic study, using solvent mixtures containing THF, dimethyl ether, and/or ether.

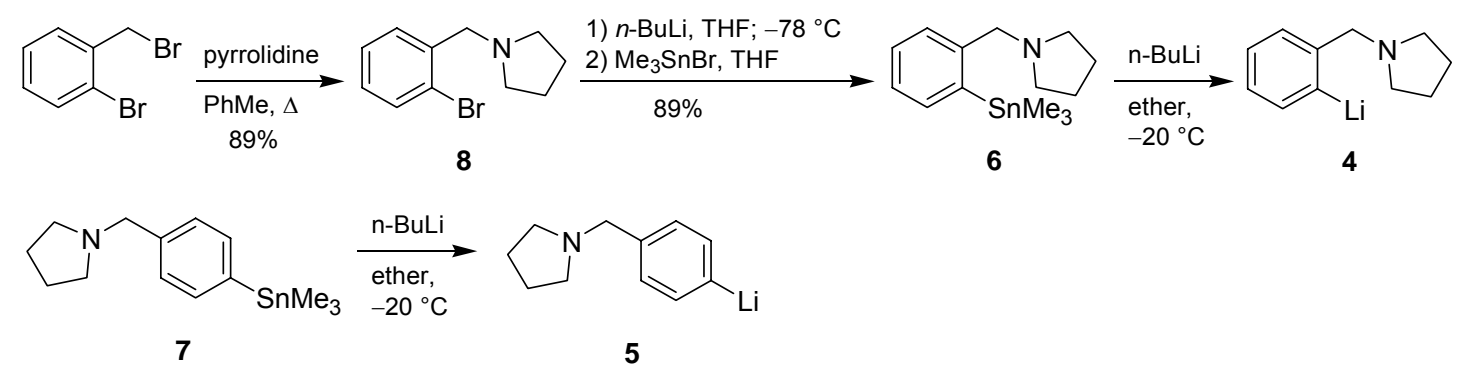

\section{Scheme 2}




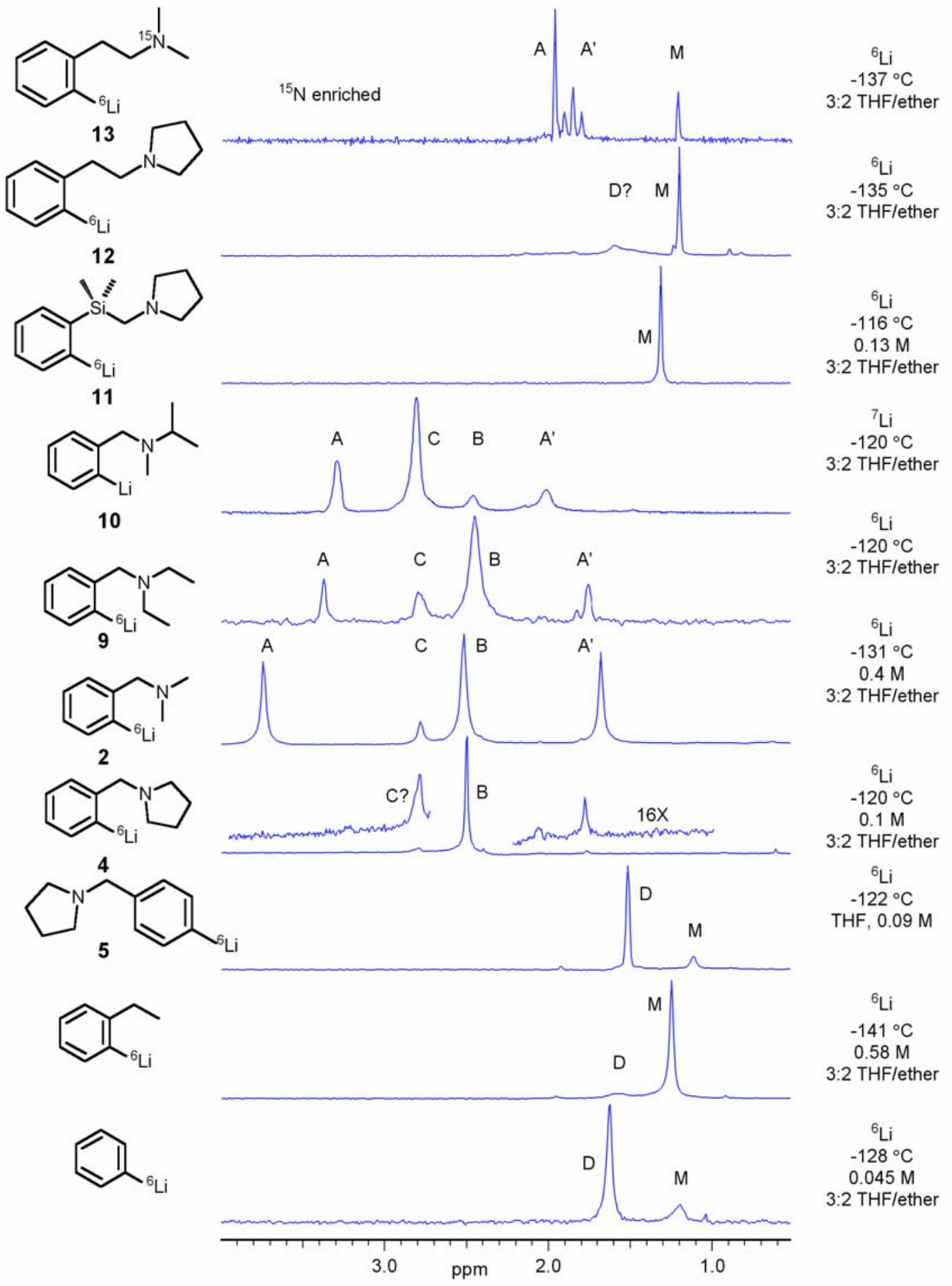

Figure 1. Low temperature ${ }^{6} \mathrm{Li} /{ }^{7} \mathrm{Li}$ NMR spectra of aryllithium reagents in $\mathrm{THF} /$ ether $(\mathbf{M}=$ monomer, $\mathbf{D}=$ dimer, for $\mathbf{A} / \mathbf{B} / \mathbf{C}$ see Figure 2). ${ }^{[7 b]}$ Chemical shifts are referenced to external 0.3 $\mathrm{M} \mathrm{LiCl}$ in methanol. 
Overview. The ${ }^{6} \mathrm{Li} /{ }^{7} \mathrm{Li}$ NMR spectra of 4, 5 and some related compounds are shown in Figure 2, together with structural assignments for the aggregates observed. ${ }^{[7 b]}$ The assignments for $\mathbf{2}, \mathbf{9}$ and 13 were confirmed by NMR studies of the ${ }^{15} \mathrm{~N}-{ }^{6} \mathrm{Li}$ doubly labeled compound. For the other benzylamines $\mathbf{4}$ and $\mathbf{1 0}$ the chemical shifts showed sufficient consistency that we have assigned those similarly. The relative amounts of the A, B and $\mathbf{C}$ chelation isomers (Figure 2) differed substantially as the N-substituents were changed. The ortho-pyrrolidinomethyl compound $\mathbf{4}$ gives essentially only one of the isomers, probably $\mathbf{B}$, with a trace of the $\mathbf{C}$ isomer.

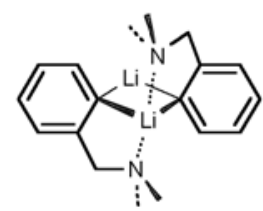

A

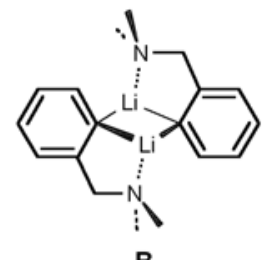

B

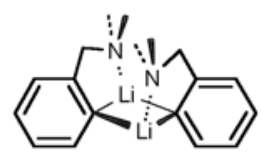

C

Figure 2. Isomers of chelated aryllithium dimers.

(a)

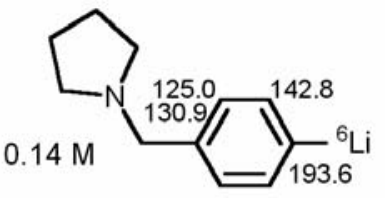

(5) $1 \quad \delta_{\mathrm{Li}}=1.12$

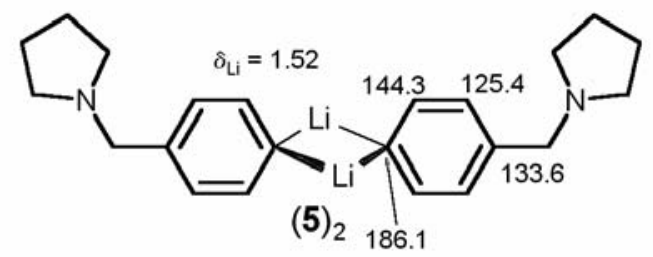

${ }^{13} \mathrm{C}$

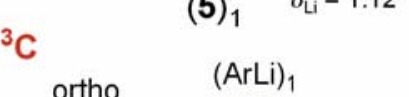

$(\operatorname{ArLi})_{2}$

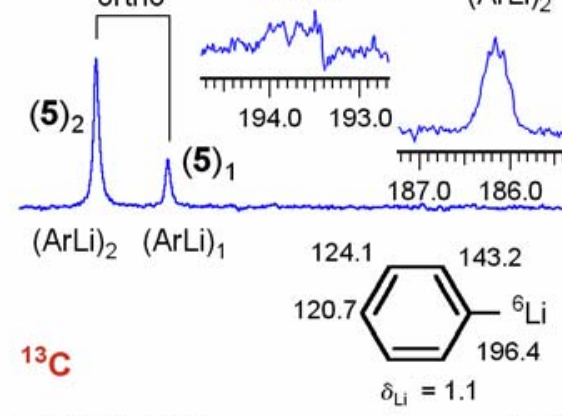

(b)

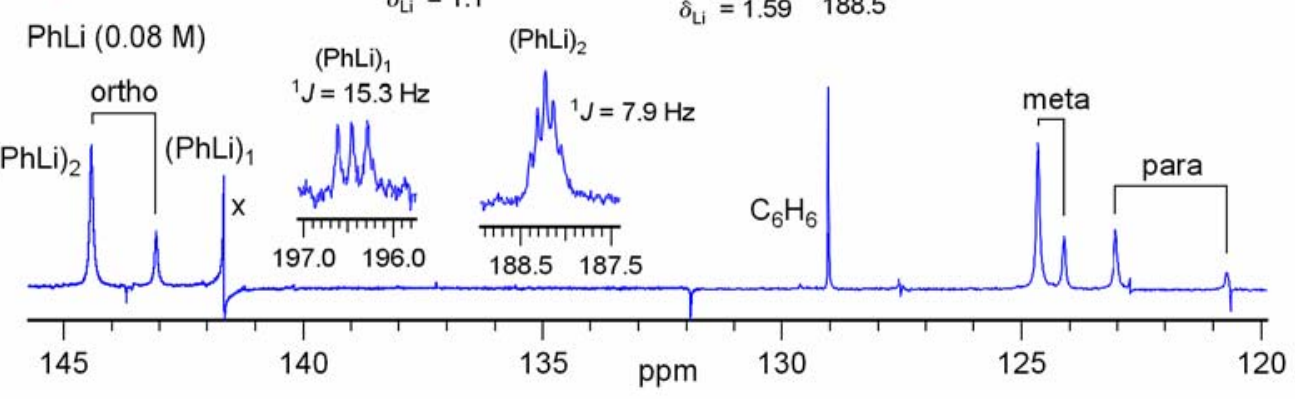

Figure 3. (a) ${ }^{13} \mathrm{C}$ NMR spectrum and chemical shift assignments of $0.14 \mathrm{M} 5-{ }^{6} \mathrm{Li}$ in THF at $118^{\circ} \mathrm{C}$. (b) ${ }^{13} \mathrm{C}$ NMR spectrum of $0.08 \mathrm{M} \mathrm{Ph}^{6} \mathrm{Li}$ in THF at $-111^{\circ} \mathrm{C} .{ }^{[7 \mathrm{c}]} \mathrm{In}$ each case the dimer is the major isomer. 
Solution structure of para-(pyrrolidinomethyl)phenyllithium (5). The solution structure of 5 is similar to that of $\mathrm{PhLi},{ }^{[7,8 \mathrm{aa}, 9,10]}$ with both dimer and monomer present in THF (Figure 3a). The ipso carbon peaks in the ${ }^{13} \mathrm{C}$ NMR spectra of the ${ }^{6} \mathrm{Li}$ enriched compound were not well enough resolved to extract coupling constants, although the peak shape is consistent with the signal at $186.1 \mathrm{ppm}$ being a 1:2:3:2:1 quintet with ${ }^{1} J_{13 \mathrm{C}-6 \mathrm{Li}}=7 \mathrm{~Hz}$. (This coupling is typically in the order of $4-5 \mathrm{~Hz}$ in tetramers, $7-8 \mathrm{~Hz}$ in dimers and $15 \mathrm{~Hz}$ in monomers ${ }^{[8 \mathrm{aa}}$ ). The other C-Li signal at $193.6 \mathrm{ppm}$ could not be resolved, but is believed to be the monomer of 5 based upon similarities in chemical shift and peak shape to the corresponding PhLi peaks (Figure 3b), which are better resolved. ${ }^{[7 \mathrm{c}]}$ Linewidth simulations suggest a ${ }^{1} J_{13 \mathrm{C}-6 \mathrm{Li}}$ of $16 \mathrm{~Hz}$.

The ${ }^{13} \mathrm{C}$ and ${ }^{6} \mathrm{Li}$ NMR spectra of a variable concentration study are presented in Figure 4a. The ${ }^{13} \mathrm{C}$ signals for the ortho carbons at 142.8 and $144.3 \mathrm{ppm}$ are ideal for analysis, and a plot of $\log$ [dimer] versus log [monomer] shown in Figure $4 \mathrm{~b}$ has a slope of $2.4 \pm 0.2$ and confirms that the two species differ in aggregation state by a factor of 2 . Even though the colligative properties of 5 were not measured, we conclude that it exists as a mixture of dimer and monomer in THF solution.

(a)

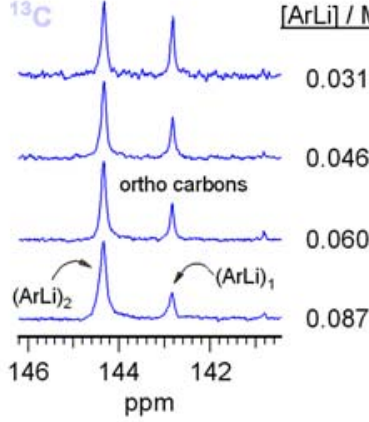

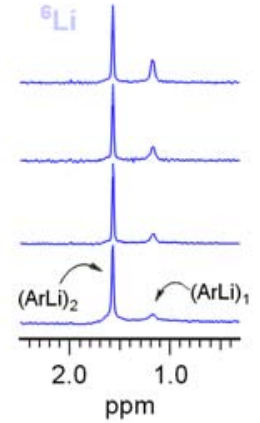

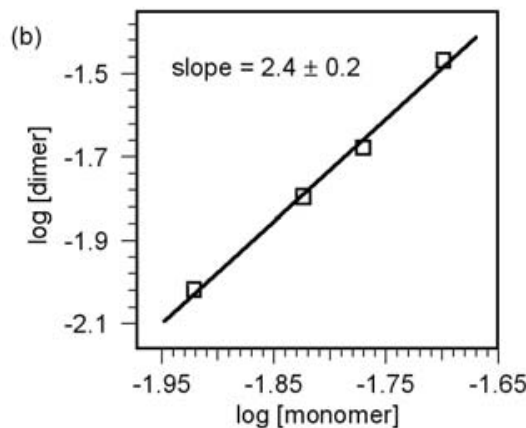

Figure 4. (a) ${ }^{13} \mathrm{C}$ and ${ }^{6} \mathrm{Li}$ NMR spectra of a variable concentration study of $5-{ }^{6} \mathrm{Li}$ in $\mathrm{THF}$ at $118^{\circ} \mathrm{C}$. (b) Plot of $\log$ [dimer] versus $\log$ [monomer] from integration of the ${ }^{13} \mathrm{C}$ NMR spectra by line shape simulation. ${ }^{[7]}$

Aggregate dynamics and thermodynamics of 5. The ${ }^{13} \mathrm{C}$ and ${ }^{6} \mathrm{Li} \mathrm{NMR}$ spectra from the variable temperature experiment of 5 in THF together with a DNMR simulation overlay is shown in Figure 5. The monomer and dimer signals of the ortho, meta, and para carbons coalesced between $-68{ }^{\circ} \mathrm{C}$ and $-100{ }^{\circ} \mathrm{C}$. A DNMR simulation of the NMR spectra gave both the ratio of the monomer-dimer populations, as well as the rate constants for their equilibration. The appropriate plots of the temperature dependence of $K_{\text {eq }}$ and rate are shown in Figure 6a and Figure 6b, leading to the kinetic and thermodynamic parameters shown in Figure 6c. The monomer-dimer association process is enthalpically neutral for both $\mathrm{PhLi}$ and 5, with the dimer being slightly favored entropically. This is commonly seen for lithium reagent aggregates, and probably arises from solvent release when two molecules of monomer, with presumably 6 coordinated solvent molecules, form one molecule of dimer, with only 4 coordinated solvent molecules. The association constant $K_{\mathrm{eq}}=\left[\right.$ Dimer] $/[\text { Monomer }]^{2}$ is $180 \mathrm{Lmol}^{-1}$ in $\mathrm{THF}$ for 5 at $-75^{\circ} \mathrm{C}$, about a factor of four larger than for $\mathrm{PhLi}$, and was observed to be temperature independent. 


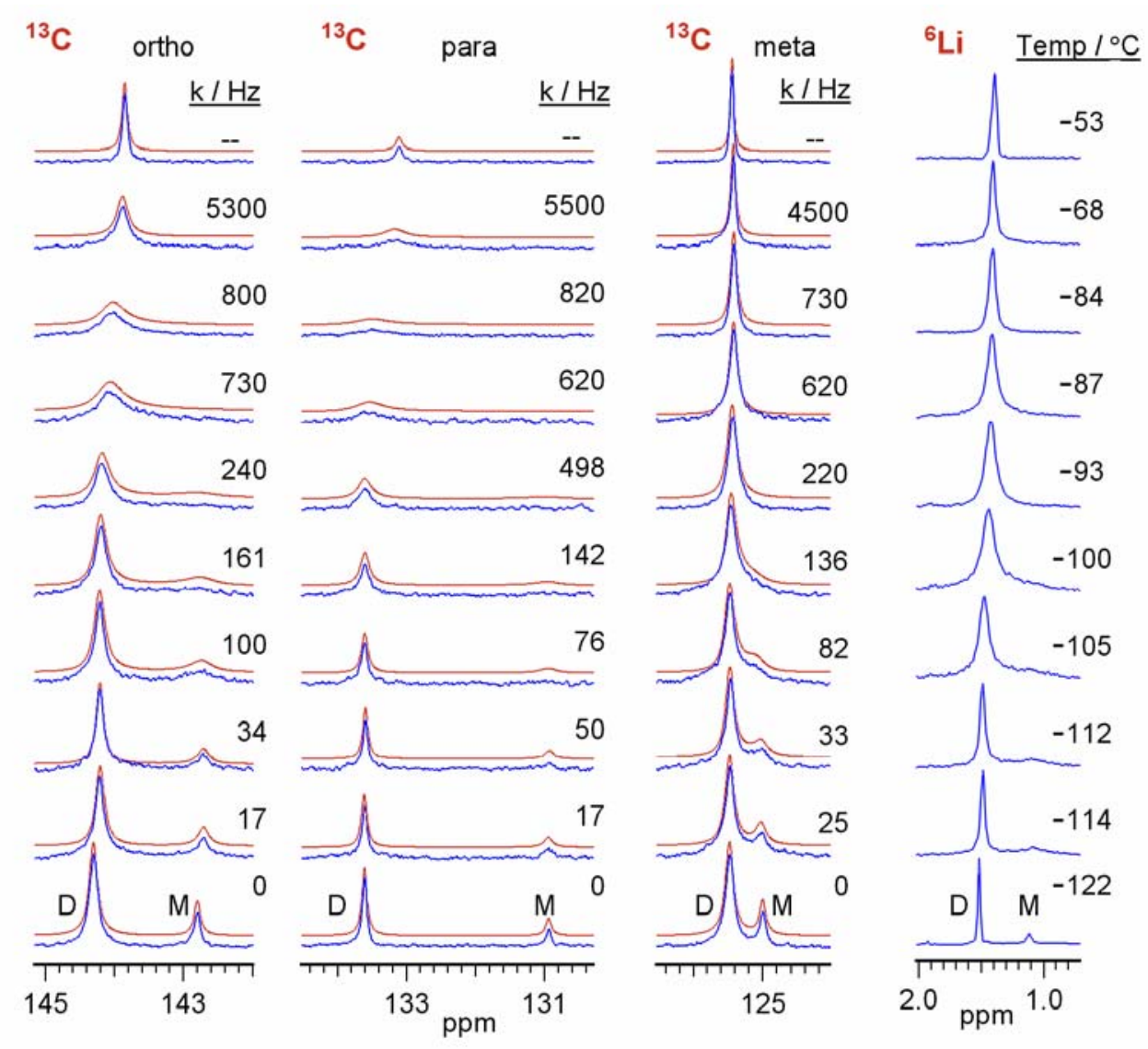

Figure 5. ${ }^{13} \mathrm{C}$ and ${ }^{6} \mathrm{Li}$ NMR spectra of a variable temperature study of $0.09 \mathrm{M} \mathrm{5-}{ }^{6} \mathrm{Li}$ in THF as well as line shape simulations ${ }^{[7 \mathrm{~d}]}$ (upper line, in red) of carbon signals.

The high precision and accuracy in the data obtained for the dynamic behavior of 5 in THF solution is in part due to the method of temperature measurement. The normal method involved removal of the sample and insertion of a thermocouple probe, which was used for the $\mathrm{PhLi}$ data, ${ }^{[7 \mathrm{c}]}$ does not measure the actual temperature of the sample nor does it correct for any temperature drifts during spectral acquisition. We used an internal chemical shift thermometer based upon the differences in the temperature-dependent ${ }^{13} \mathrm{C}$ chemical shifts of the methyl and methine carbons of tris(trimethylsilyl)methane. ${ }^{[7 \mathrm{e}]} \mathrm{A}$ small amount of the chemically-inert ${ }^{13} \mathrm{C}$ thermometer was added directly to the sample and allowed precise internal temperatures to be measured.

Interaction of 5 with TMEDA. TMEDA $\left(N, N, N^{\prime} N^{\prime}\right.$-tetramethylethylenediamine) is a commonly used additive for modifying the behavior of organolithium derivatives. ${ }^{[11]}$ We routinely examine the effects of TMEDA when defining solution structures of organolithium reagents. The addition of TMEDA to 5 in THF produces a series of three complexes, the monomer TMEDA complex $\mathbf{M}-\mathbf{L}_{\mathbf{1}}$, and the mono and bis TMEDA complexes of the dimer ( $\mathbf{D}-\mathbf{L}_{\mathbf{1}}$ and $\left.\mathbf{D}-\mathbf{L}_{\mathbf{2}}\right)$. This behavior is very similar to that observed for $\mathrm{PhLi} .^{[7 \mathrm{c}]}$ 
(a)

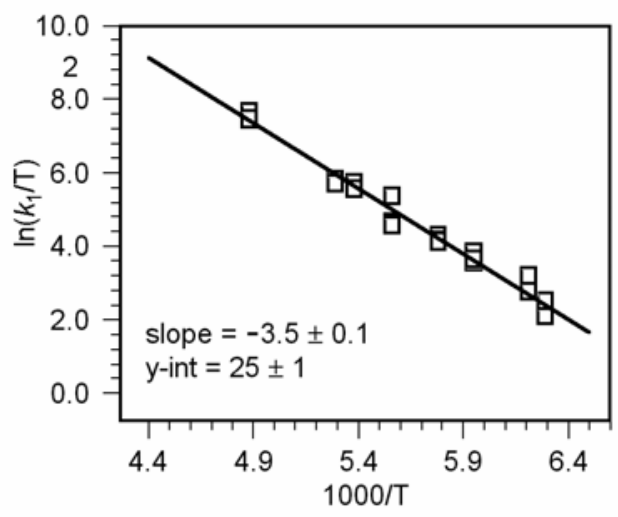

(b)

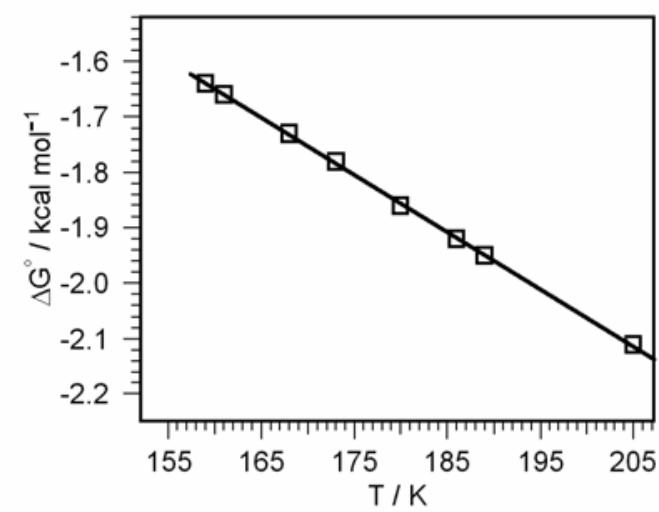

(c)

2

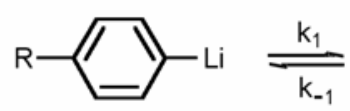

$\mathrm{R}=\mathrm{CH}_{2} \mathrm{~N}\left(\mathrm{CH}_{2}\right)_{4} \quad \mathrm{R}=\mathrm{H}$

$\Delta \mathrm{H}_{1}{ }^{*} / \mathrm{kcal} / \mathrm{mol} \quad 7.0 \pm 0.2 \quad 7.5 \pm 0.1$

$\Delta \mathrm{H}_{-1}{ }^{\top} / \mathrm{kcal} / \mathrm{mol}$

$\Delta \mathrm{H}^{\circ} / \mathrm{kcal} / \mathrm{mol}$

$$
7.0 \pm 0.2 \quad 7.0 \pm 0.1
$$$$
0 \pm 0.01
$$

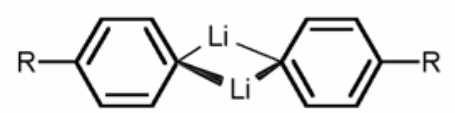

$$
\begin{array}{lcr} 
& \mathrm{R}=\mathrm{CH}_{2} \mathrm{~N}\left(\mathrm{CH}_{2}\right)_{4} & \mathbf{R}=\mathbf{H} \\
\Delta \mathrm{S}_{1}{ }^{\dagger} / \mathrm{cal} \mathrm{mol}^{-1} \mathrm{~K}^{-1} & 2 \pm 2 & 2.5 \pm 1 \\
\Delta \mathrm{S}_{-1}{ }^{\dagger} / \mathrm{cal} \mathrm{mol}^{-1} \mathrm{~K}^{-1} & -7 \pm 2 & -7.4 \pm 1 \\
\Delta \mathrm{S}^{\circ} / \mathrm{cal} \mathrm{mol}^{-1} \mathrm{~K}^{-1} & 10.3 \pm 0.1 & 10 \pm 2
\end{array}
$$

Figure 6. A plot of (a) $\ln \left(k_{1} / \mathrm{T}\right)$ versus $1 / \mathrm{T}$ and (b) $\Delta \mathrm{G}^{\circ}$ versus temperature for $0.09 \mathrm{M} 5$ in THF. The data is for the ortho, meta and para carbons. (c) Activation and thermodynamic parameters for 5 and $\mathrm{PhLi}$ in THF.
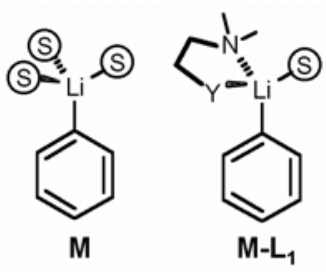

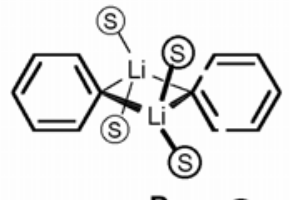

D (S) $=$ solvent

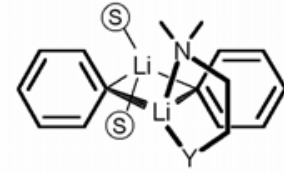

D- $L_{1}$

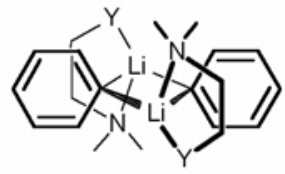

D- $L_{2}$

\section{Figure 7}

The $\mathbf{M}-\mathbf{L}_{\mathbf{1}}$ species in several aryllithiums investigated have been very dynamically active, with decoalescence between the complexed and uncomplexed species requiring temperatures below $-125{ }^{\circ}{ }^{[7 b, 7 c]}$ Thus, in THF solution the $\mathbf{M}$ and $\mathbf{M}-\mathbf{L}_{\mathbf{1}}$ signals cannot be decoalesced (Figure 8a) and a single averaged peak was observed, which moved downfield as more TMEDA was added. There was a small increase in the fraction of monomer as TMEDA was added, so TMEDA complexes monomer only slightly more effectively than dimer. This was also seen for PhLi. ${ }^{[7 c]}$ The competition between TMEDA and THF solvent is such that a substantial excess of TMEDA needs to be added before more than $80 \%$ of the lithium reagent is converted to $\mathbf{D}-\mathbf{L}_{2}$. In Figure $8 \mathrm{~b}$ we report on a lower temperature experiment using the mixed solvent THF/ $\mathrm{Me}_{2} \mathrm{O} /$ ether $(3: 2: 1)$ which provided better resolved spectra. The less polar solvent resulted in a slightly higher dimer to monomer ratio and more effective binding of TMEDA. ${ }^{[11 a, 12]}$ 
(a)
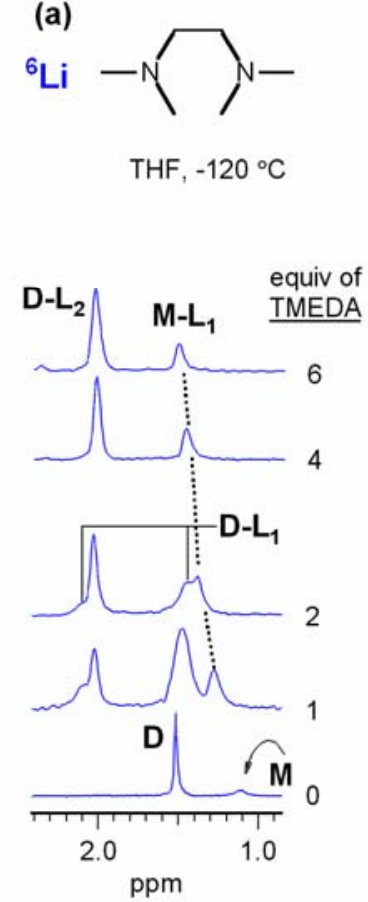

(b)

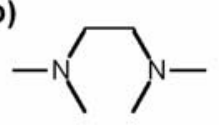

3:2:1 $\mathrm{THF} / \mathrm{Me}_{2} \mathrm{O} / \mathrm{Et}_{2} \mathrm{O}$ -130 to $-137^{\circ} \mathrm{C}$

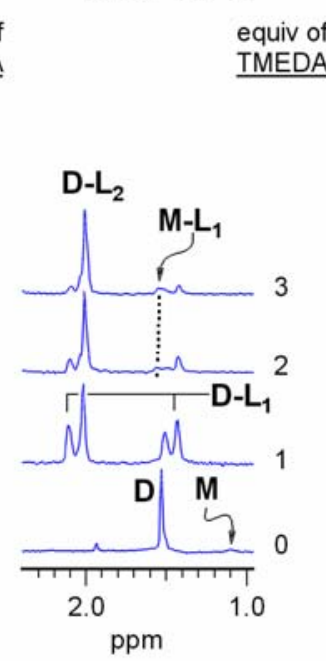

(c)

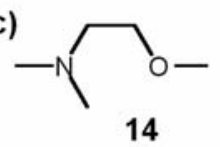

3:2:1

$\mathrm{THF} / \mathrm{Me}_{2} \mathrm{O} / \mathrm{Et}_{2} \mathrm{O}$ -135 to $-142^{\circ} \mathrm{C}$
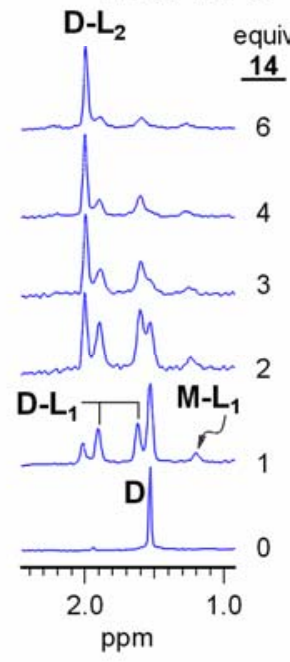

(d)

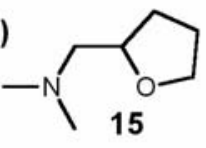

3:2:1

$\mathrm{THF} / \mathrm{Me}_{2} \mathrm{O} / \mathrm{Et}_{2} \mathrm{O}$ -130 to $-140^{\circ} \mathrm{C}$
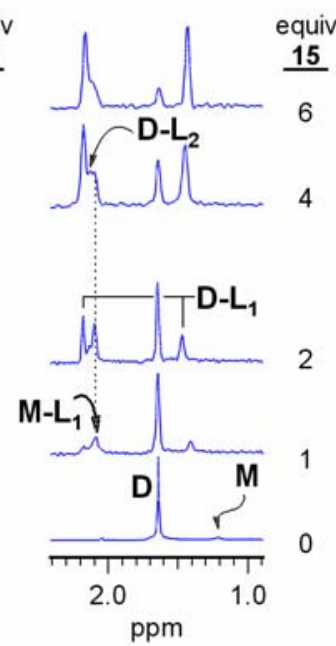

Figure 8. (a) ${ }^{6} \mathrm{Li}$ NMR spectra of a TMEDA titration of $0.09 \mathrm{M} \mathrm{5-}{ }^{6} \mathrm{Li}$ in $\mathrm{THF}$ at $-110^{\circ} \mathrm{C}(L=$ TMEDA). (b) ${ }^{6} \mathrm{Li}$ NMR spectra of a TMEDA titration of $0.09 \mathrm{M} \mathrm{5-}{ }^{6} \mathrm{Li}$ in $\mathrm{THF} / \mathrm{Me}_{2} \mathrm{O} / \mathrm{ether}$ (3:2:1) at -130 to $-137{ }^{\circ} \mathrm{C}(\mathrm{L}=\mathrm{TMEDA})$. (c) ${ }^{6} \mathrm{Li} \mathrm{NMR}$ spectra of an $N, N$-dimethyl-2-methoxyethylamine $(\mathrm{L}=14)$ titration of $0.14 \mathrm{M} \mathrm{5}-{ }^{6} \mathrm{Li}$ in $\mathrm{THF} / \mathrm{Me}_{2} \mathrm{O} /$ ether $(3: 2: 1)$ at -135 to $-142{ }^{\circ} \mathrm{C}$. (d) ${ }^{6} \mathrm{Li} N \mathrm{NM}$ spectra of 2-(dimethylaminomethyl)tetrahydrofuran $(\mathrm{L}=15)$ titration of $0.09 \mathrm{M} \mathrm{5-}{ }^{6} \mathrm{Li}$ in $(3: 2: 1) \mathrm{THF} / \mathrm{Me}_{2} \mathrm{O} /$ ether at -130 to $-140{ }^{\circ} \mathrm{C}$.

We also examined the effects of two other bidentate additives on the structure of 5 in the search of a better ligand than TMEDA. We chose 14 and the THF analog 15 for this purpose, since 14 has been shown to be more effective than TMEDA in binding dimeric lithium amides. $^{[11 \mathrm{~b}]}$ We were also interested in comparing the effects of amine versus ether chelation. The addition of $\mathbf{1 4}$ to 5 in $\mathrm{THF} / \mathrm{Me}_{2} \mathrm{O} /$ ether formed a similar set of complexes as observed for TMEDA (Figure $8 \mathrm{c}$ ). The ${ }^{6} \mathrm{Li}$ NMR spectra show a pair of signals at $\delta 1.60$ and 1.90 in a $1: 1$ ratio for the mono-ligand complex of $(\mathbf{5})_{2}$ dimer, $\left(\mathbf{D}-\mathbf{L}_{\mathbf{1}}\right)$, and a singlet at $\delta 2.0$ for the biscomplex D-L2. The possible cis and trans isomers of the bis-complex $\mathbf{D}-\mathbf{L}_{2}$ could not be distinguished in the ${ }^{6} \mathrm{Li} \mathrm{NMR}$ spectra. A comparative analysis of the ${ }^{6} \mathrm{Li}$ NMR spectra in Figure $8 \mathrm{~b}$ and $7 \mathrm{c}$ at 2 equiv of co-solvent reveals that TMEDA is a better ligand than 14 . The ${ }^{6} \mathrm{Li} \mathrm{NMR}$ spectra in Figure 8b show the expected two signals for $\mathbf{D}-\mathbf{L}_{\mathbf{1}}$ at $\delta 1.44$ and $\delta 2.11 \mathrm{ppm}$ and a signal for $\mathbf{D}-\mathbf{L}_{2}$ at $\delta 2.03 \mathrm{ppm}$.

It would be reasonable to predict that 2-(dimethylaminomethyl)tetrahydrofuran (15) would be a better chelator than $\mathbf{1 4}$ and possibly TMEDA, because THF is generally a stronger donor solvent than dimethyl ether. (Methyl-substituted tetrahydrofurans ${ }^{[11 c, 13]}$ have similar dipole 
moments and dielectric constants to those of $\mathrm{Me}_{2} \mathrm{O}$ and only slightly lower ones than those of THF). However, the coordination of $\mathbf{1 5}$ to 5 was noticeably weaker than that of $\mathbf{1 4}$ (Figure 8d) or TMEDA. It also shows a higher fraction of conversion to monomer. There are clear indications of cooperativity in the formation of $\mathbf{D}-\mathbf{L}_{\mathbf{1}}$ and $\mathbf{D}-\mathbf{L}_{\mathbf{2}}$ for the bidentate ligands, with TMEDA and 14 favoring $\mathbf{D}-\mathbf{L}_{2}$, whereas 15 strongly favors $\mathbf{D}-\mathbf{L}_{\mathbf{1}}$. There is ample precedent for idiosyncratic behavior in the coordination of mono and polydentate ligands to lithium aggregates. ${ }^{[11 \mathrm{~b}, 11 \mathrm{~d}]}$ Apparently the open binding sites in the substrate are too sterically hindered for what we expected to be better bidentate ligands for lithium. ${ }^{[11 \mathrm{a}]}$

Interaction of $\mathbf{5}$ with dimethylethylamine. To test for the possibility that $\mathbf{5}$ might experience cooperative and/or competitive effects from the para-pyrrolidino substituent we performed a dimethylethylamine titration on 5 in THF (Figure 9a). The addition of the monodentate amine appears to have little to no effect on the structure of 5 in THF solution, so it is unlikely that the para-pyrrolidinomethyl group is actively involved in the solution structure (e.g., in intermolecular coordination to form oligomeric aggregates). This experiment also confirms that 14 and $\mathbf{1 5}$ are behaving as bidentate ligands since they do affect the structure.

(a)

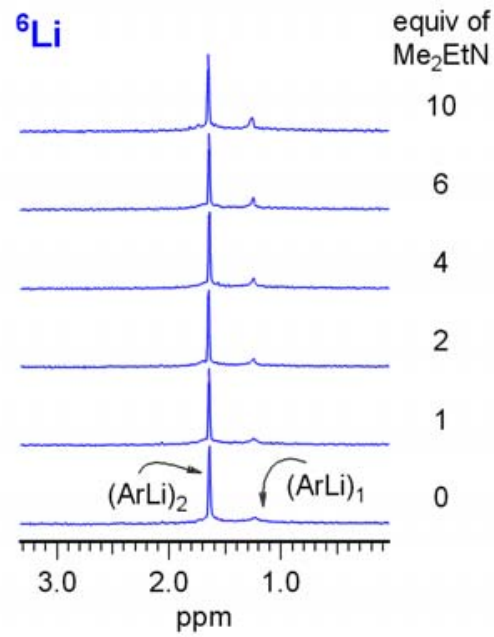

(b)

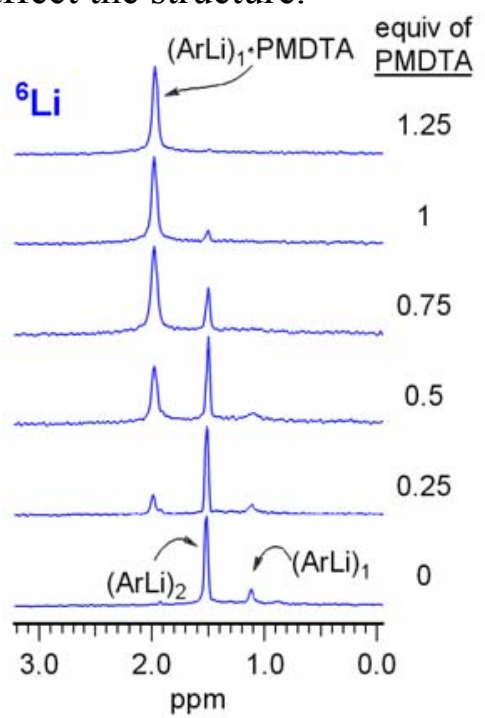

Figure 9. (a) ${ }^{6} \mathrm{Li}$ NMR spectra of a dimethylethylamine titration of $0.09 \mathrm{M} \mathrm{5}-{ }^{6} \mathrm{Li}$ in $\mathrm{THF}$ at $-121{ }^{\circ} \mathrm{C}$. (b) ${ }^{6} \mathrm{Li}$ NMR spectra of a PMDTA titration of $0.09 \mathrm{M} \mathrm{5-}{ }^{6} \mathrm{Li}$ ) in THF at $-120{ }^{\circ} \mathrm{C}$.

Interaction of 5 with PMDTA. The PMDTA $\left(N, N, N^{\prime}, N^{\prime \prime}, N^{\prime \prime}\right.$-pentamethyldiethylenetriamine) titration of 5 in THF solution is presented in Figure $9 \mathrm{~b}$ and shows the formation of the monomeric PMDTA complex (5) $\bullet$ PMDTA at $\delta 1.98$ in the ${ }^{6} \mathrm{Li}$ NMR spectra. The complexation is not quite stoichiometric since the peak at $\delta 1.52$ for the dimer of 5 is still visible at 1 and 1.25 equiv of PMDTA. ${ }^{[7 \mathrm{c}]}$ The signal at $\delta 1.12$ for the THF-solvated monomer is broadened during the titration and is no longer visible past 0.5 equiv of PMDTA; perhaps the monomer is exchanging with the (5) $)_{1} \bullet$ PMDTA complex on the NMR time scale at $-120^{\circ} \mathrm{C}$. 
ortho-Pyrrolidinomethylphenyllithium (4). The ${ }^{13} \mathrm{C}$ (Figure 10) and Li NMR (Figure 1) spectral properties of $\mathbf{4}$ are consistent with the presence of a single isomer of a chelated dimer. From the similarities of ${ }^{6} \mathrm{Li}$ chemical shift to that of the $\mathbf{B}$ isomer of the dimethylamino (2), diethylamino (9), and isopropylmethylamino analogs (10), in which all three chelation isomers were present (Figure 1), ${ }^{[7 \mathrm{a}]}$ we conclude that this is the $\mathbf{B}$ isomer. The surprisingly different $\mathbf{A} / \mathbf{B} / \mathbf{C}$ ratios of $\mathbf{4}$ and $\mathbf{2}$ are not well understood, but must arise from a complex interplay between steric effects within the dimer structure and interactions with the coordinated solvent molecules. ${ }^{[7 \mathrm{a}]}$ No peaks in the ${ }^{13} \mathrm{C},{ }^{6} \mathrm{Li}$ or ${ }^{7} \mathrm{Li} \mathrm{NMR}$ spectra could be unambiguously assigned to the monomer. There is a small signal in the ${ }^{6} \mathrm{Li}$ NMR spectrum (ca 3.5\%) which could be a monomer. This corresponds to an association $K_{\mathrm{eq}}>4000 \mathrm{M}^{-1}$.

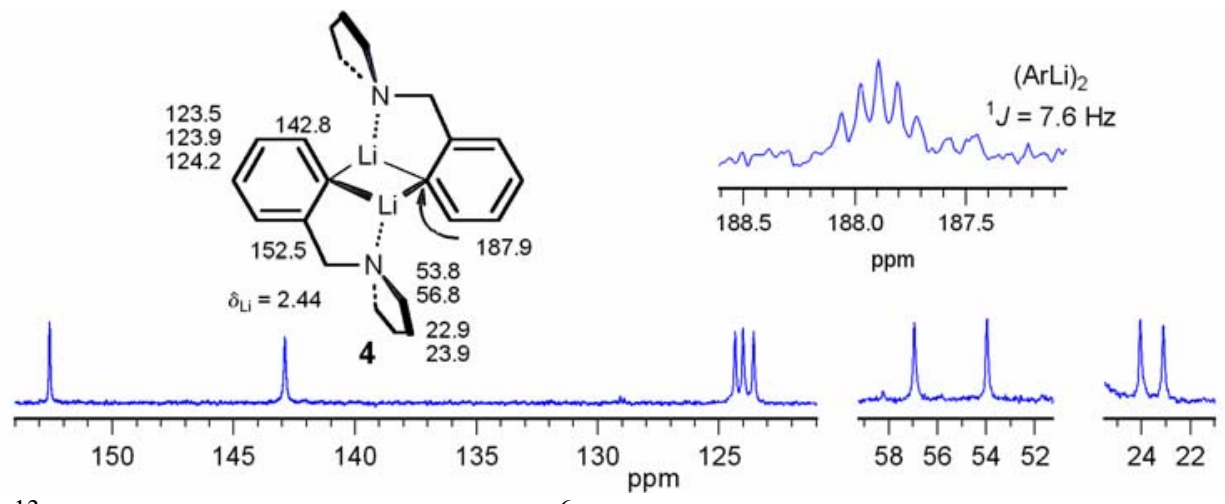

Figure 10. ${ }^{13} \mathrm{C}$ NMR spectrum of $0.13 \mathrm{M} \mathrm{4}-{ }^{6} \mathrm{Li}$ in THF/ether $(3: 2)$ at $-123{ }^{\circ} \mathrm{C}$.

Solid state structure of 4 . X-ray quality crystals of $(4)_{2}-A \cdot(T H F)_{2}$ were grown from THF-ether solution at $-78{ }^{\circ} \mathrm{C}$. The compound is a chelated dimer of the B-type in the solid state (Figure 11), with the open coordination sites filled by THF molecules. This supports the solution structural assignment. The structure is very similar to the previously reported structure of $N$-isopropyl- $N$ methylaminomethylphenyllithium, ${ }^{[7 \mathrm{a}]}$ with bond distances of 2.18 and $2.22 \AA$ for the $\mathrm{C}$-Li bonds, $2.11 \AA$ for the Li-N bond, and $1.93 \AA$ for the $\mathrm{Li}-\mathrm{O}$ bond. The central $\mathrm{C}_{2} \mathrm{Li}_{2}$ ring is distorted in the usual way, with a Li-C-Li angle of $67.27(10)^{\circ}$ and C-Li-C angle of $112.73(10)^{\circ}$.
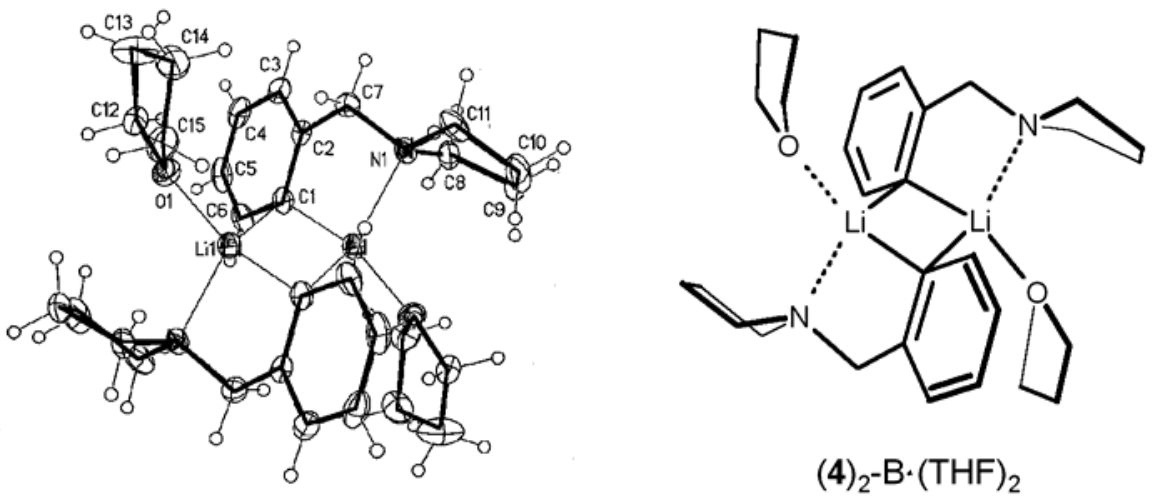

Figure 11. X-ray crystal structure of $(4)_{2}-\mathrm{B} \cdot(\mathrm{THF})_{2}$. The displacement ellipsoids were drawn at the $50 \%$ probability level. The molecule occupies a crystallographic inversion center. 
Dynamic studies of 4. The presence of only one isomer prevents use of Li NMR spectra to obtain information about intra-aggregate exchange, as was done for 2. However, the compound is well suited for ${ }^{13} \mathrm{C}$ NMR spectroscopy because the presence of only one chelation isomer simplifies spectra compared to the analogues 2 and $9 .{ }^{13} \mathrm{C}$ NMR spectra of three regions in the spectra, the $\mathrm{C}-1$ carbon at $\delta 188$, the $\mathrm{N}-\underline{\mathrm{CH}} \mathrm{H}_{2}$ carbons at $\delta 54-57$ and the $\mathrm{N}-\mathrm{CH}_{2}-\underline{\mathrm{CH}}_{2}$ at $\delta 23-24$ at a selection of temperatures are shown in Figure 12. Both the $\alpha$ and $\beta$ carbons in the pyrrolidine rings are diastereotopic, and their coalescences can be followed. This process showed $\Delta G^{\ddagger}$ values rather similar to the A-B-C interconversion of 2, although the solvents are slightly different (3: 2 THF/ether for 4 compared to pure THF for 2). This exchange could either result from rotation around the C-1-C-1' axis without breaking the Li-N bond, via 4-C, or decoordination-recoordination, via 4-A. The former process, if it were the only one occurring, could be detected by the absence of scrambling of $\mathrm{Li}^{15}{ }^{15} \mathrm{~N}$ coupling, but we were not able to do this experiment because ${ }^{15} \mathrm{~N}$ enriched 4 was not available and natural abundance ${ }^{15} \mathrm{~N}$ NMR experiments failed. From the similarity of the activation energies for interconversion of A-B-C isomers of $\mathbf{2}$ (which requires decoordination of the chelating ligand for the interconversion of the $\mathbf{A}$ isomer with the $\mathbf{B} / \mathbf{C}$ isomers) and the pyrrolidine ring rotation of $\mathbf{4}$ it seems likely that the latter process also involves o oamine dechelation.

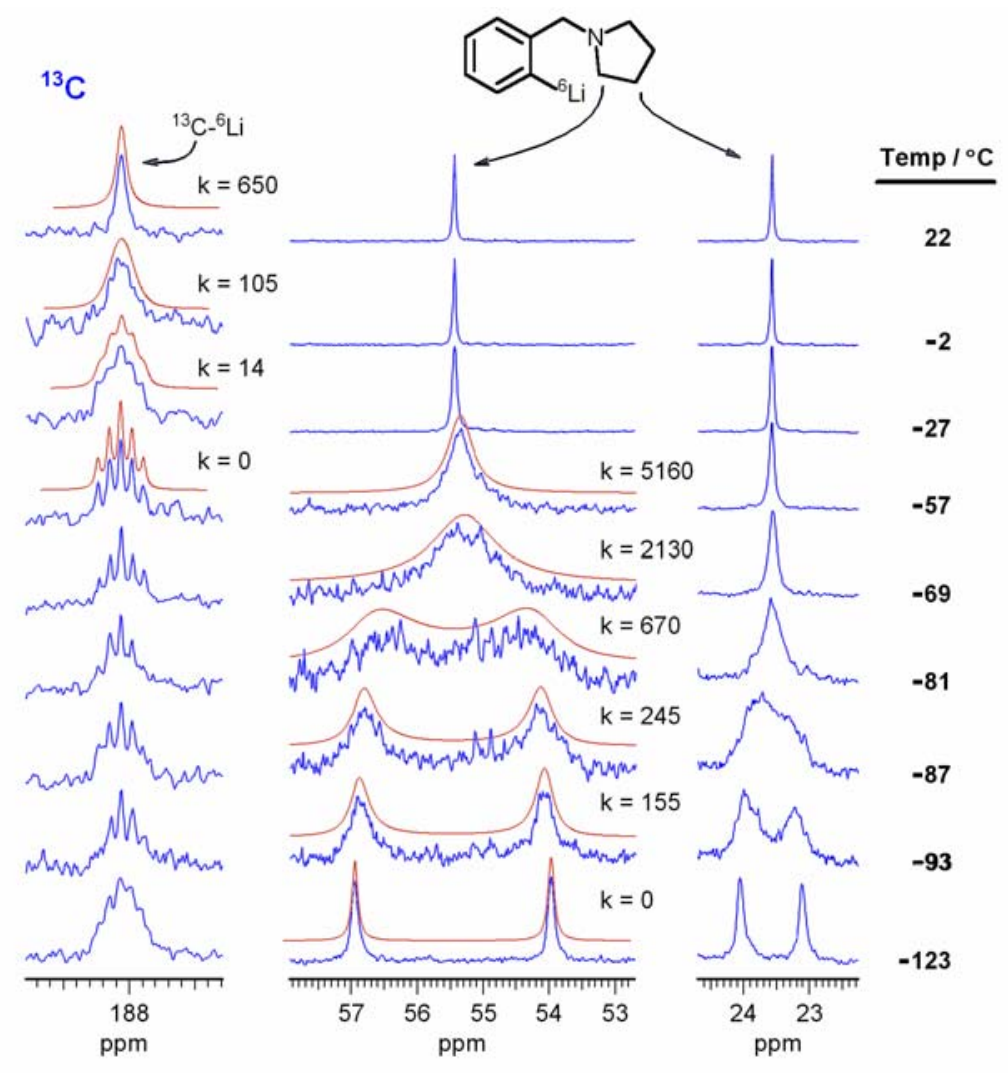

Figure 12. Selected spectra from a variable temperature ${ }^{13} \mathrm{C}$ NMR spectroscopic study (ipso aryl carbon at $\delta 188, \mathrm{~N}-\underline{\mathrm{CH}}_{2}$ carbons at $\delta 55$, and $\mathrm{N}-\mathrm{CH}_{2}-\underline{\mathrm{CH}}_{2}$ carbons at $\left.\delta 23.5\right)$ of $0.16 \mathrm{M} 4$ in $\mathrm{THF} / \mathrm{Et}_{2} \mathrm{O}(3: 2)$ and simulated line shapes (upper curve in red) with rate constants for exchange. 
The $\mathrm{C}$-Li coupling is lost above $-20{ }^{\circ} \mathrm{C}$ (Figure 12), signaling the onset of interaggregate exchange. We performed line shape simulations of this process using the exchange matrix derived from a random exchange mechanism previously reported. ${ }^{[7]}$ Simulation using a dimertetramer mechanism gave the same line shapes. Simulated spectra for $\mathbf{5}$ are shown in Figure 12, the rates and some comparisons with data for $\mathbf{2}$ are summarized in the graph of Figure 13. Activation energies $\left(\Delta G^{\ddagger}\right)$ for loss of C-Li coupling were ca $13 \mathrm{kcal} / \mathrm{mol}$ for 4 , very similar to those of $2^{[7 \mathrm{a}]}$

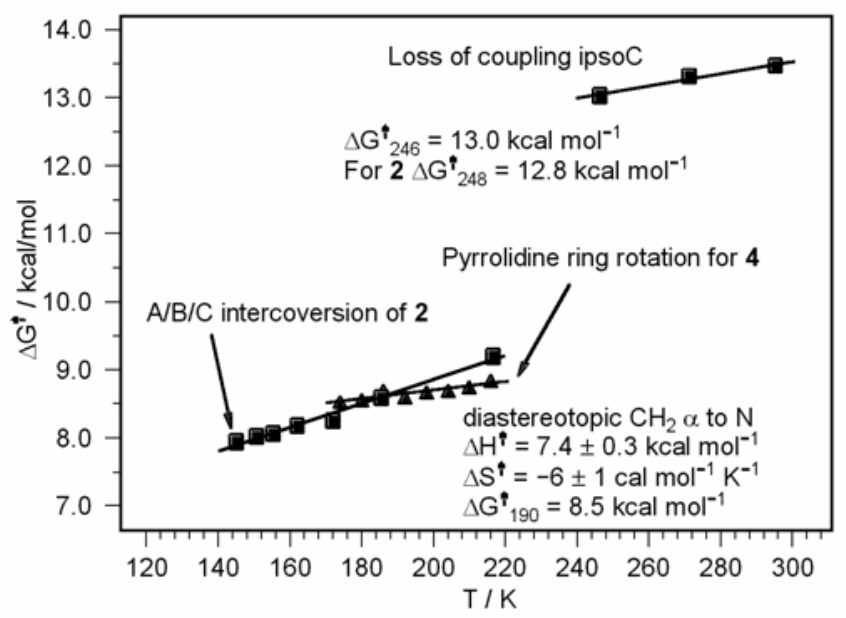

Figure 13. Dynamic processes for 4 in $\mathrm{THF} / \mathrm{Et}_{2} \mathrm{O}(3: 2)$, and comparison with 2 in THF.

Interaction of 4 with TMEDA. The addition of TMEDA to THF solutions of $\mathbf{4}$ had almost no effect on the solution structure (Figure 14). This is presumably a consequence of the high preference of $\mathbf{4}$ for the $\mathbf{B}$ structure (Figure 2) over the A structure, since only the latter can complex a bidentate ligand. This is in contrast to $\mathbf{2}$, for which the $\mathbf{A}$ isomer is the major one, and which easily forms bidentate A-type complexes with both TMEDA and PMDTA. ${ }^{[7]}$
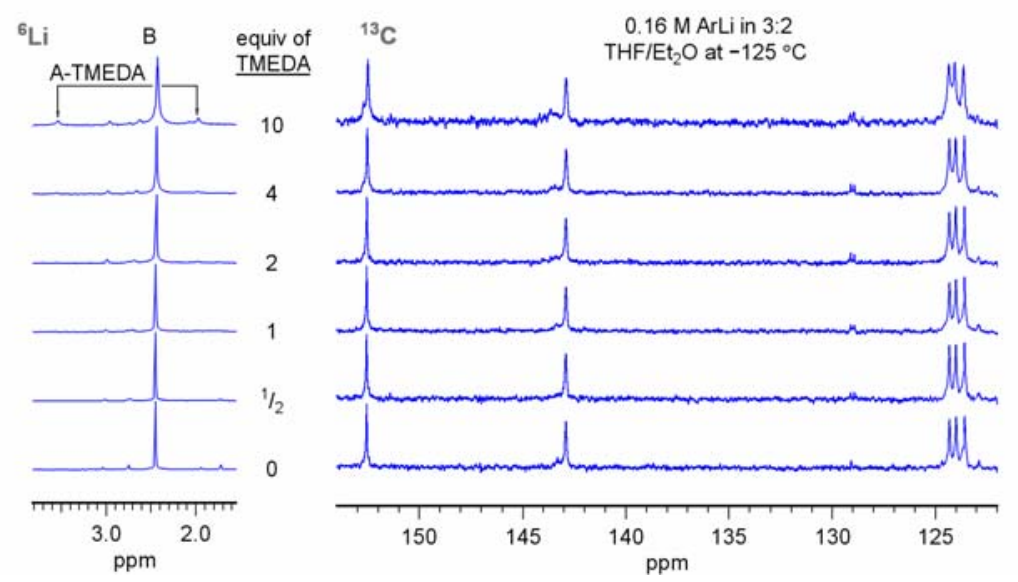

Figure 14. TMEDA titration of a $0.16 \mathrm{M}$ solution of 4 in $\mathrm{THF} / \mathrm{Et}_{2} \mathrm{O}(3: 2)$ at $-125{ }^{\circ} \mathrm{C}$. 
In the TMEDA titration small changes in the ${ }^{6} \mathrm{Li}$ spectra were seen at high equivalents of the ligand, notably the appearance of two small singlets with chemical shifts of $\delta 1.97$ and 3.54 (about $8 \%$ conversion at 10 equiv. of TMEDA), nearly identical to those of (2) 2 -A $\cdot$ TMEDA. We assign these to $(4)_{2}$-A $\cdot$ TMEDA. ( ${ }^{15} \mathrm{~N}$ labeled 4 was not available for a more secure identification). A $K_{\text {eq }}$ for association $\left[(\mathbf{4})_{2}+\mathrm{TMEDA}=(\mathbf{4})_{2}\right.$-A $\bullet$ TMEDA] was $0.09 \mathrm{~L} / \mathrm{mol}$, about $1 / 90$ that of 2 .

Mixtures of phenyllithium with 4. One of the most puzzling aspects of the chemistry of the chelated aryllithium reagents is the strong propensity to form dimers under conditions where phenyllithium, $o$-tolyllithium and analogs are significantly or entirely monomeric. ${ }^{[7 c]}$ Therefore, we examined mixtures of $\mathbf{4}$ with PhLi to see whether a mixed dimer formed and how it behaved in solution. Figure 15 shows some data from an experiment of this type. Two new signals appeared, one close to the signal for $\mathrm{PhLi}$, and other close to the signal for 4 , which can be assigned to the mixed dimer 16. The two lithiums of $\mathbf{1 6}$ are nonequivalent below $-115{ }^{\circ} \mathrm{C}$ so decoordination is slow on the NMR time scale. The equilibrium constant for mixed dimer formation $\left[(4)_{2}+(\mathrm{PhLi})_{2}=2(\mathbf{1 6})\right]$ was measured as $K_{\mathrm{eq}}=27$. The statistical value would be $K_{\mathrm{eq}}$ $=4$.
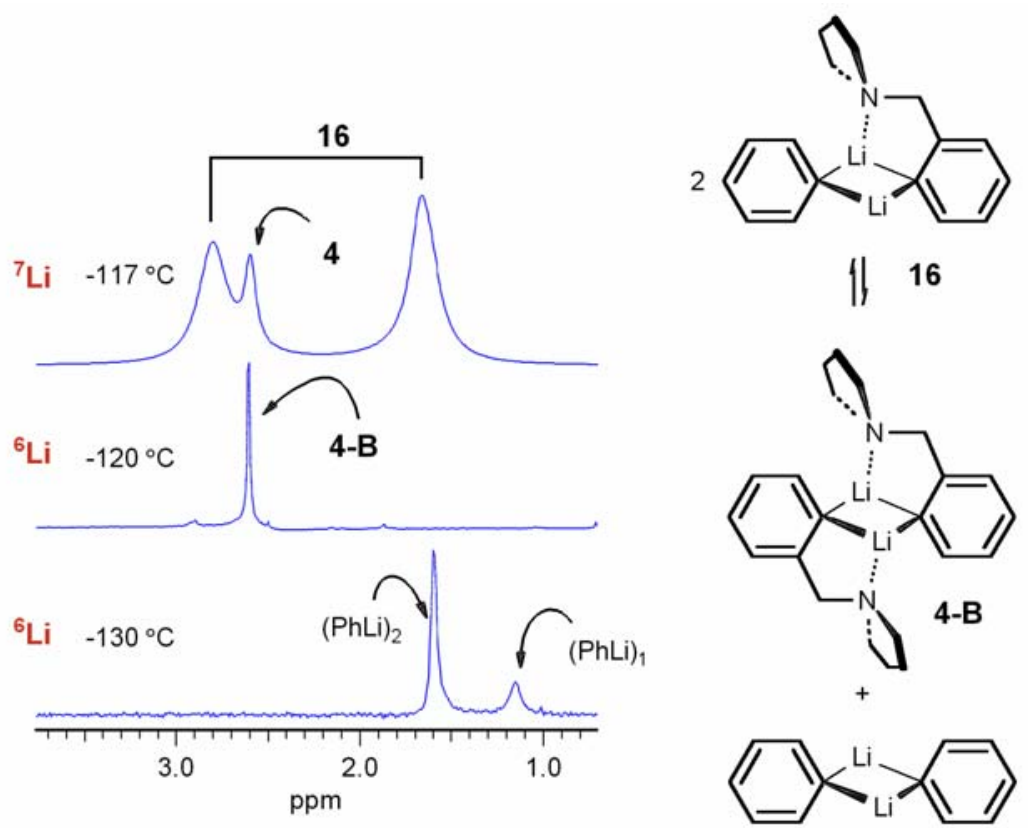

Figure 15. Lithium NMR spectra of PhLi, 4, and a 1:1 mixture (containing mainly the mixed dimer 16) in THF/ether (3:2).

A variable-temperature ${ }^{7} \mathrm{Li}$ NMR study was done with the mixed dimer solution, shown in Figure 16. A complex series of line-shape changes was seen as the temperature was raised, involving first equilibration of the two lithium signals of the mixed dimer, so that at $-60{ }^{\circ} \mathrm{C}$ there are three signals for 4, 16, and the averaged signals of $(\mathrm{PhLi})_{2} /(\mathrm{PhLi})_{1}$. $(\mathrm{PhLi}$ dimer and 
monomer are coalesced below this temperature). Next, the mixed dimer $\mathbf{1 6}$ signals coalesce with the $\mathrm{PhLi}$ signals leading to two signals at $-32{ }^{\circ} \mathrm{C}$. Above $-32{ }^{\circ} \mathrm{C} 4$ finally begins to exchange with the other lithium species present. The experiment was performed at two concentrations differing by a factor of 4 to establish whether the interaggregate exchanges were associative (i.e., going through mixed tetramers) or dissociative (via monomers). Spectra could be simulated well with three rate constants, representing the three phases of the DNMR process: (1) $-116{ }^{\circ} \mathrm{C}$ to $67{ }^{\circ} \mathrm{C}$, the coalescence of the two signals of the mixed dimer, $k_{\mathrm{DD}}$; (2) $-67{ }^{\circ} \mathrm{C}$ to $-32{ }^{\circ} \mathrm{C}$, coalescence of the mixed dimer with $\mathrm{PhLi}, k_{\mathrm{DP}} ;(3)-32{ }^{\circ} \mathrm{C}$ to $-6{ }^{\circ} \mathrm{C}$, coalescence of $(4)_{2}$ with the average of the mixed dimer 16 and $(\mathrm{PhLi})_{2}, k_{\mathrm{BD}}$. Our simulation ignored the exchange of $\mathrm{PhLi}$ monomer and dimer, since there is only a little monomer PhLi present and this quickly coalesces with the dimer around $-100{ }^{\circ} \mathrm{C}$. The small broadening of the $(\mathrm{PhLi})_{2}$ signal caused by this exchange was corrected for by a small increase in the inherent line width.
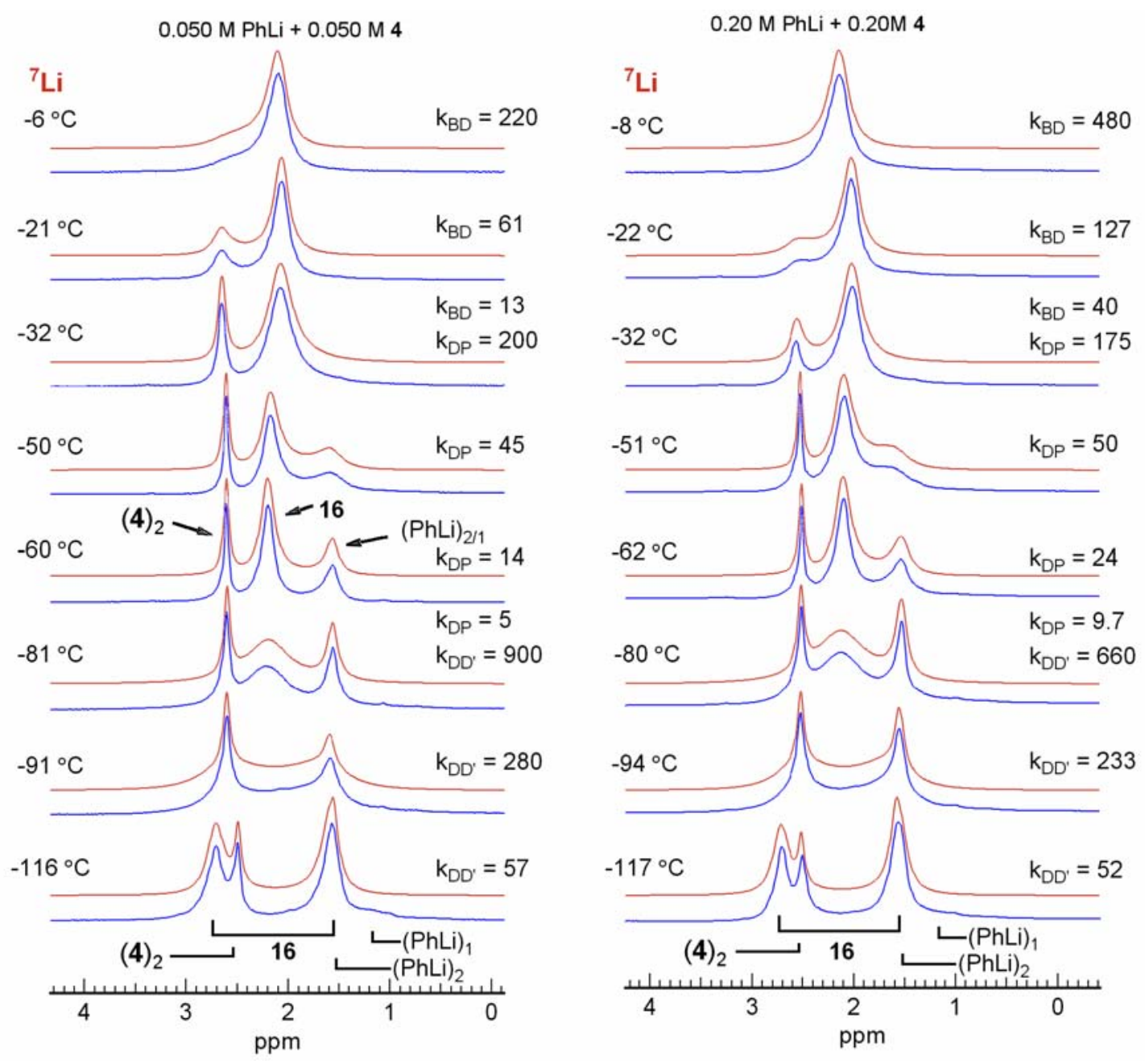

Figure 16. Selected spectra from a variable temperature ${ }^{7} \mathrm{Li}$ NMR study of a mixture of PhLi and 4 in THF/ether (3:2) at two concentrations (0.050 and $0.20 \mathrm{M})$. At each temperature the lower curve is the experimental spectrum (in blue) and the upper the simulation (in red). 
As seen from the $\Delta G^{\ddagger}$ vs $T$ plot in Figure 17, the interconversion of the two lithium signals of 16 (process $1, k_{\mathrm{DD}^{\prime}}$ ) shows identical rates at the two concentrations, as expected for an intramolecular rearrangement. The data for the rates of mixed dimer-PhLi exchange (process 2, $k_{\mathrm{DP}}$ ), is more ambiguous. The rates for the high-concentration sample are consistently higher than those of the low-concentration one, but by a factor of 1.3-1.5. This is smaller than the factor of two expected for a fourfold change in concentration through a mechanism involving interconversion through mixed tetramers. Because the line shapes in the temperature range from $-67{ }^{\circ} \mathrm{C}$ to $-32{ }^{\circ} \mathrm{C}$ where process (2) dominates are to some extent affected by both process (1) and (3), as well as by the coalescence of PhLi dimer and monomer at the lower temperatures, the accuracy of the rate constants is lower, perhaps insufficient to establish molecularity. Alternatively, the exchange mechanism for process (2) could involve monomeric $\mathrm{PhLi}$ (which is present in significant concentration) exchanging with 16 through a mixed trimer, ${ }^{[8 \mathrm{~b}]}$ with an expected order of 1.5, or both associative (2nd order) and dissociative (1st order) mechanisms are simultaneously operative.

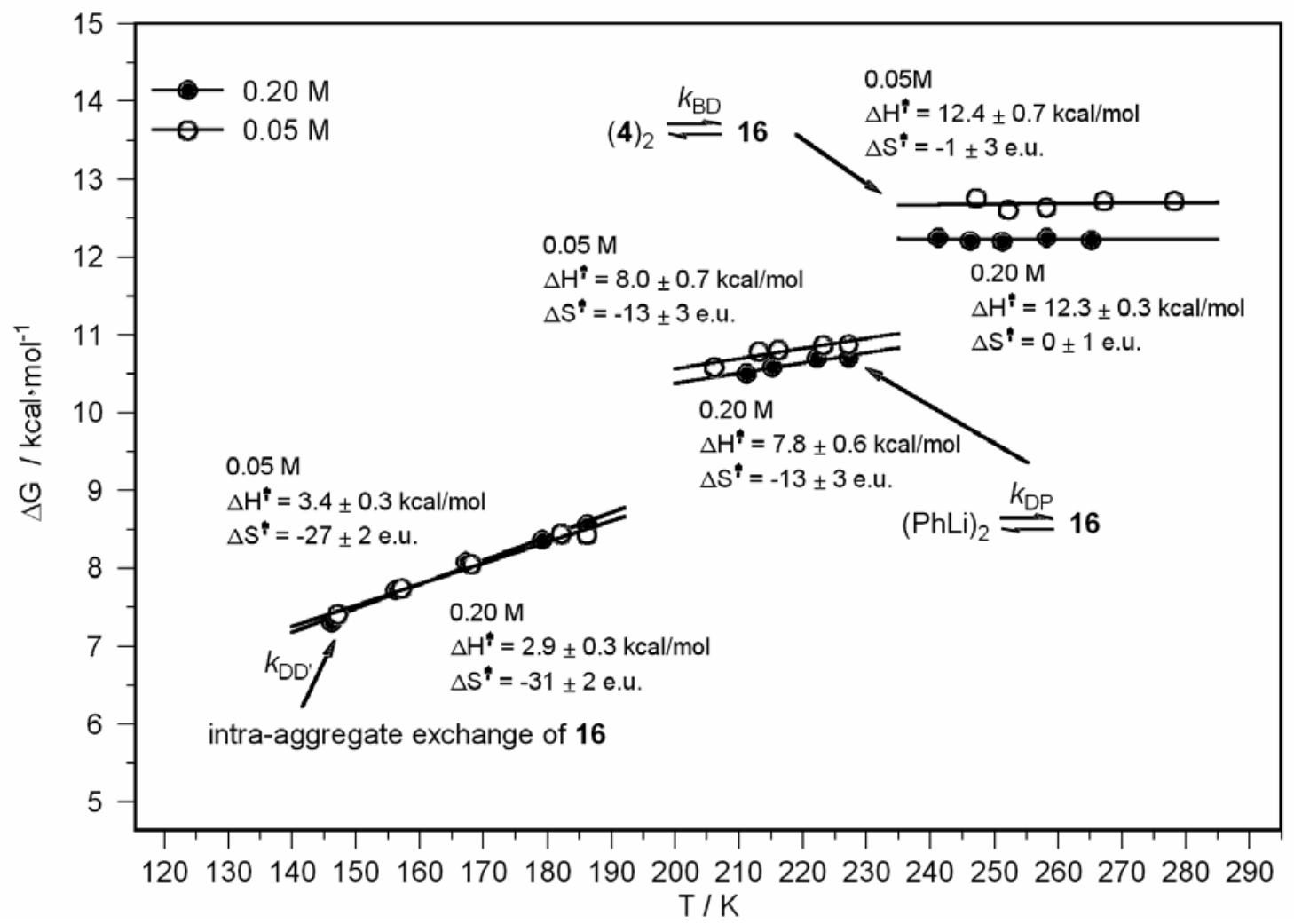

Figure 17. Activation parameters for the dynamic processes involving homo and mixed dimers

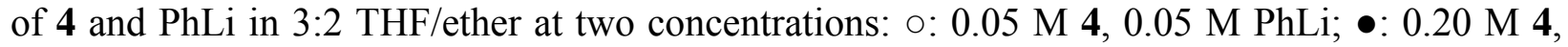
$0.20 \mathrm{M} \mathrm{PhLi}$.

The exchange between (4) $)_{2}$ and the averaged signal of 16 and $\mathrm{PhLi}$ (process $3, \mathrm{k}_{\mathrm{BD}}$ ), is clearly at least second order (rate ratios of 2.06 to 2.43 for the two samples differing in 
concentration by a factor of four), so here, as for the intermolecular exchange of the homodimer $2,{ }^{[7]}$ a mechanism involving the transient formation of mixed tetramers is the likely path. The barrier obtained for interaggregate exchange of $(4)_{2}$ and $\mathbf{1 6}\left(\Delta G^{\ddagger} 44=12.4 \mathrm{kcal} / \mathrm{mol}\right)$ is a little lower than that obtained from loss of coupling in (4) (Figure 13, $\Delta G^{\ddagger} 246=13.0 \mathrm{kcal} / \mathrm{mol}$ ), so 16 is more reactive towards $(4)_{2}$ than is $(4)_{2}$.

Lithium-iodine exchange of 4 . We have had a long-standing interest in the mechanism of the lithium-metalloid exchange reactions. ${ }^{[7 \mathrm{~g}, 14,15]}$ To assess the effect of chelation on the $\mathrm{Li} / \mathrm{I}$ exchange reaction, we performed a ${ }^{13} \mathrm{C}$ variable temperature NMR study of a mixture of 4 and the corresponding iodide $\mathbf{1 7}$ for comparison with non-chelated models (Figure 18). Both the thermodynamic and dynamic behavior are drastically different than for the $\mathrm{PhLi} / \mathrm{PhI}$ system. Even at the lowest temperature no trace of the ate complex 18 can be seen, so $K_{\text {eq-ate }}<0.19 \mathrm{M}^{-1}$ ( $\Delta G^{\circ}>0.5 \mathrm{kcal} / \mathrm{mol}$, we estimate $5 \%$ of ate complex would have been detected). For $\mathrm{PhLi} / \mathrm{PhI}$, $K_{\text {eq-ate }}$ at this temperature in the slightly more polar solvent $10: 1 \mathrm{THF} / \mathrm{ether} K_{\text {eq-ate }}=4400 \mathrm{M}^{-1}$ $\left(\Delta G^{\circ}=-2.5 \mathrm{kcal} / \mathrm{mol}\right),{ }^{[7 \mathrm{~g}, 14]}$ at least a factor of 22,000 larger, with $\mathrm{Ph}_{2} \mathrm{I}^{-} \mathrm{Li}^{+}$more than 3 $\mathrm{kcal} / \mathrm{mol}$ more stable than $\mathbf{1 8}$ compared to the precursor lithium reagents and iodides.

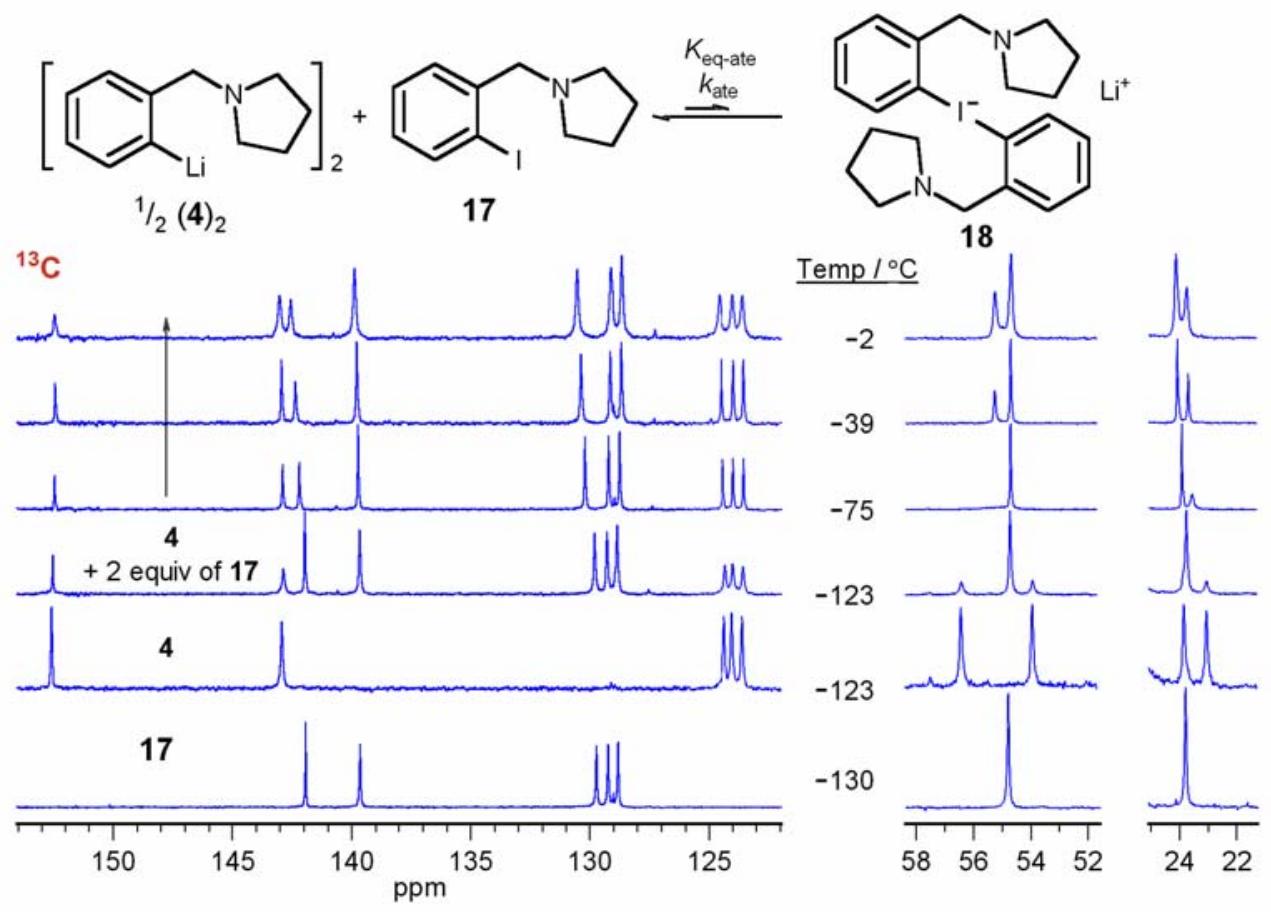

Figure 18. ${ }^{13} \mathrm{C}$ variable temperature NMR spectra of 17,4 , and a sample containing $0.13 \mathrm{M} 4$ and $0.26 \mathrm{M} 17$ in THF/ether (3:2).

The ${ }^{13} \mathrm{C}$ signals in $\mathrm{PhLi} / \mathrm{PhI},{ }^{[7 \mathrm{~g}]}$ and other ArLi/ArI pairs are fully coalesced at temperature even below $-123{ }^{\circ} \mathrm{C}$, whereas the signals of both $\mathbf{1 7}$ and $\mathbf{4}$ were distinctly visible even up to $2{ }^{\circ} \mathrm{C}$. The sample began to decompose above $-2{ }^{\circ} \mathrm{C}$. At this temperature some line broadening 
was observed, with an excess line width at half height for the iodide of ca $5 \mathrm{~Hz}$, corresponding to a rate constant of $16 \mathrm{sec}^{-1}$ (second order rate constant $k_{\text {ate }} \leq 121 \mathrm{Lmol}^{-1} \mathrm{sec}^{-1}, G^{\ddagger} \geq 13.2 \mathrm{kcal} / \mathrm{mol}$ ). This broadening may signal the onset of mutual exchange between the iodide and lithium reagent. At this temperature the rate of the $\mathrm{PhLi} / \mathrm{PhI}$ exchange can be estimated at $1 \times 10^{7}$ $\mathrm{mol}^{-1} \mathrm{sec}^{-1}, \Delta G^{\ddagger}=7.2 \mathrm{kcal} / \mathrm{mol} .^{[14 \mathrm{a}]}$ The ca $6 \mathrm{kcal} / \mathrm{mol}$ higher barrier $\left(10^{5}\right.$ higher rate $)$ is probably directly related to the at least $5 \mathrm{kcal} / \mathrm{mol}$ higher barrier for dimer dissociation for $\mathbf{4}$ compared to 5 and $\mathrm{PhLi}$ (the measured barrier for aggregate exchange of $\mathbf{4}$ is for an associative process, the dissociative process must have a higher barrier) and suggests that dissociation to monomer is a prerequisite for the $\mathrm{Li} / \mathrm{I}$ exchange process. This was also observed for several non chelated $\mathrm{Li} / \mathrm{M}$ exchanges, where the monomer is the reactive species and the dimer was found to be inert. ${ }^{[14]}$

Potential 6-ring chelate compounds 11 and 12. We have previously reported on the solution structure of $o$-(2-dimethylaminoethyl)phenyllithium. ${ }^{[7 \mathrm{~b}]}$ The compound was present as a mixture of dimer and monomer, with the interesting property that the dimer was chelated and had the $\mathbf{A}$ structure, as indicated by the observation of Li-N coupling, but the monomer was unchelated (Fig 1).

Examination of the ${ }^{6} \mathrm{Li} \mathrm{NMR}$ spectra of the pyrrolidine analog 12 (Figure 1) showed that the compound was largely monomeric. Similarly, compound 11 was entirely monomeric in THF/ether (3:2) (Figure 19) with a well-defined 1:1:1:1 quartet for the C-Li carbon $\left({ }^{1} J_{13 \mathrm{C}-7 \mathrm{Li}}=36 \mathrm{~Hz}\right)$. The ${ }^{15} \mathrm{~N}$ labeled compounds were not prepared so it was not established whether the compounds were chelated.

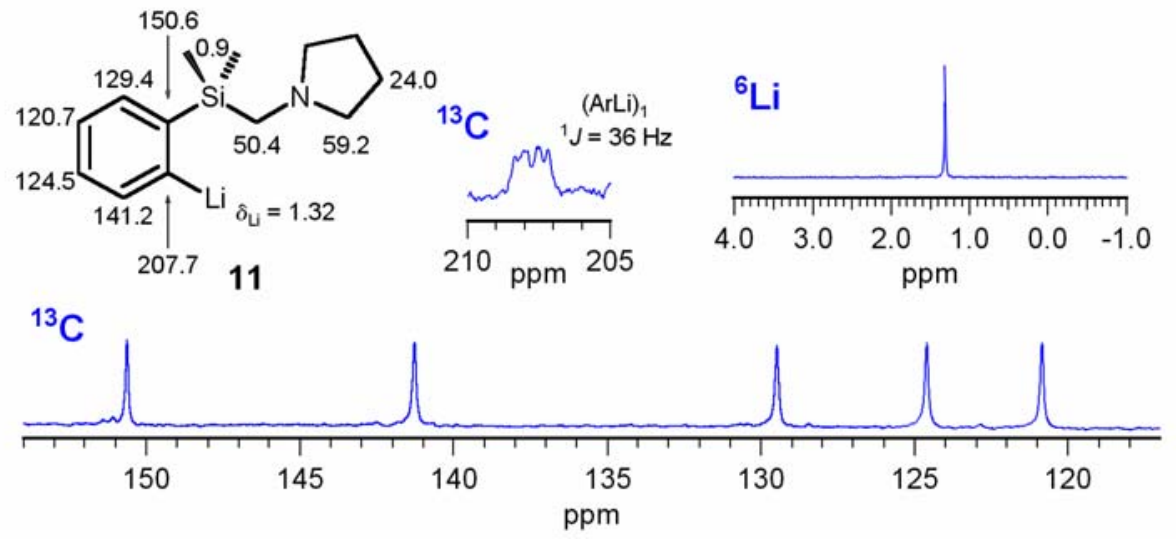

Figure 19. ${ }^{7} \mathrm{Li}$ and ${ }^{13} \mathrm{C}$ NMR spectra of 11 in THF/ether $(3: 2)$ at $-117{ }^{\circ} \mathrm{C}$.

Tin-oxygen and tin-nitrogen chelation in the precursor stannanes. Organotin compounds with one or more electronegative substituents $(\mathrm{Cl}, \mathrm{Br}, \mathrm{OR})$ show well defined Lewis acidic properties, ${ }^{[4 f, 16,17]}$ whereas tetraorganotin compounds are generally viewed as having no such properties. ${ }^{[18]}$ Previous studies in these laboratories have shown that even simple tetraalkyl and tetraaryl stannanes form ate complexes $\left(\mathrm{R}_{5} \mathrm{Sn}^{-} \mathrm{Li}^{+}\right)$with alkyl and aryllithium reagents, ${ }^{[7 i]}$ suggesting considerable residual Lewis acidity even without stabilizing substituents on tin. We 
have measured the ${ }^{119} \mathrm{Sn}$ NMR chemical shifts of most of the organotin compounds used in this study and previous ones. ${ }^{[7 \mathrm{a}, 7 \mathrm{~b}]}$ A stacked plot is shown in Figure 20. The compounds with orthosubstituents which cannot chelate and those which can form 6- or 7-membered ring chelates show identical chemical shifts of around $\delta 34$, and so in these compounds there is no interaction between tin and the heteroatom. However, all of the compounds with pendant groups that can form 5-ring chelates show the characteristic upfield shifts of pentacoordinate tin compounds, amounting to $5 \mathrm{ppm}$ for ether chelation and 20-30 ppm for amine chelation. In addition, significant Sn-N $J$ coupling is observed for the diethylaminomethyl compound $\mathbf{9}$. The chelation is weak, since fully developed pentacoordinate tin compounds have upfield shifts of several hundred ppm, and Sn-N coupling constants of $100 \mathrm{~Hz}$ or more. Similar observations were reported by Ruzicka et al. ${ }^{[19]}$

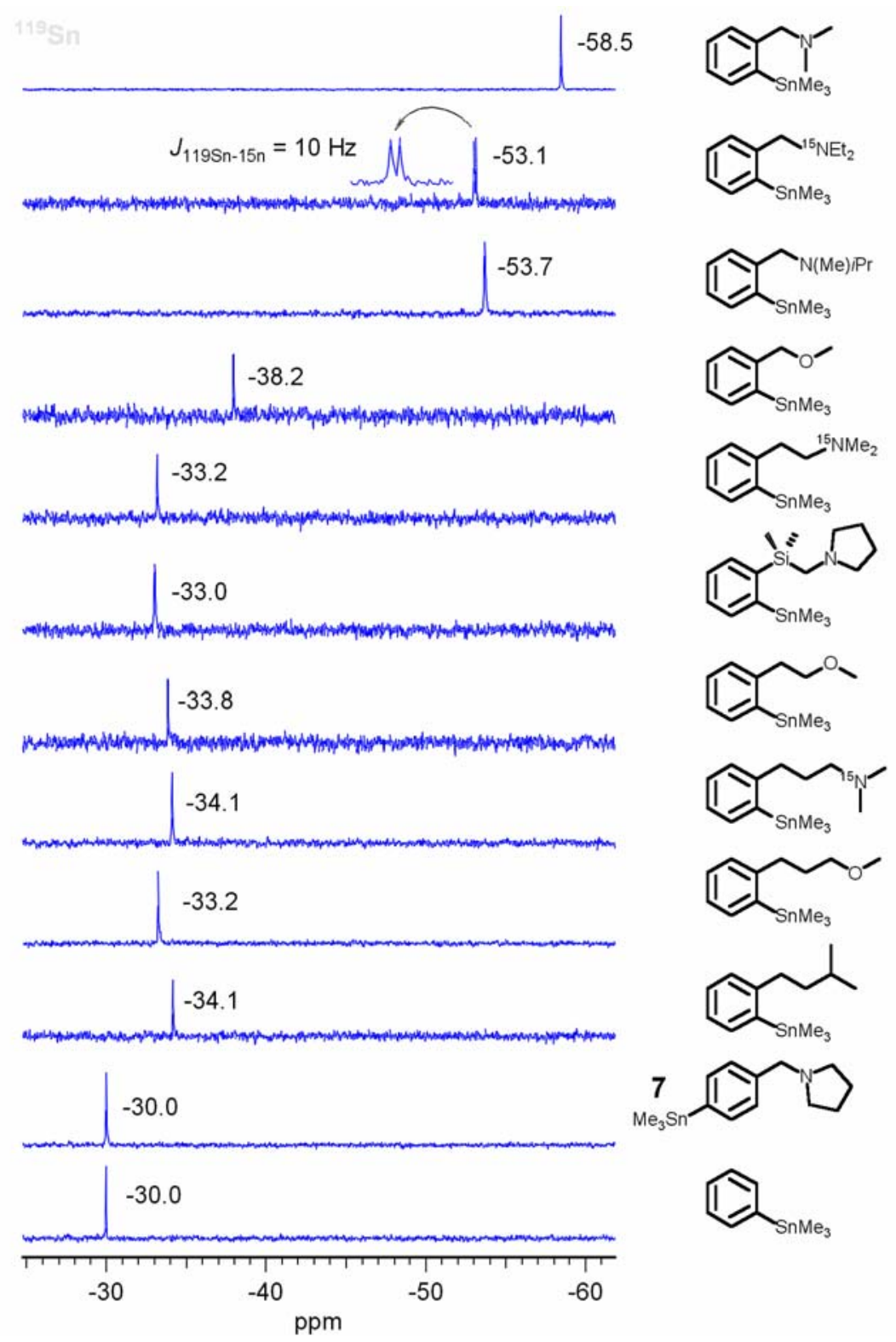

Figure 20. ${ }^{119} \mathrm{Sn}$ NMR spectra of aryl tin compounds with potential chelating groups. 


\section{Summary}

The solution behavior of $\mathbf{5}$ in THF is strikingly similar to that of $\mathrm{PhLi} .{ }^{[7 \mathrm{cc}]}$ The monomer-dimer equilibrium is shifted a little towards the dimer in the para-substituted aryllithium, presumably a consequence of the inductive effects of the para-pyrrolidinomethyl group. The parapyrrolidino group remains a spectator and plays no additional role in the solution behavior of 5 in THF. Several bidentate ligands (TMEDA, 14 and 15) form complexes with monomeric 5, as well as mono- and bis-complexes with dimeric 5. PMDTA and HMPA convert 5 completely to monomer at one equivalent of additive.

Reagent 4 is a B-type dimer in crystals grown from THF solution as well as in THF solution. As was also seen for several other ortho- $N, N$-dialkylaminomethylphenyllithium derivatives, ${ }^{[7 a]}$ the chelated compound is much more strongly dimerized than the model parasubstituted analog, with the barrier for aggregate exchange over $5 \mathrm{kcal} / \mathrm{mol}$ higher in the chelated (4) compared to the model compound (5). This higher aggregation propensity is probably directly related to the much lower reactivity of $\mathbf{4}$ in the degenerate $\mathrm{Li} / \mathrm{I}$ exchange reaction, which is at least a factor of 100,000 slower than the $\mathrm{PhLi} / \mathrm{PhI}$ exchange. With $\mathrm{PhLi}, 4$ forms a thermodynamically favored mixed dimer, 16, which is also more strongly dimerized than $\mathrm{PhLi}$, with a barrier to aggregate interchange about $3 \mathrm{kcal} / \mathrm{mol}$ higher than that for $\mathrm{PhLi}$. Compound $\mathbf{4}$ is only slightly complexed by TMEDA, with only a few percent of a Type-A TMEDA complex at 10 equiv of cosolvent.

\section{Experimental Section}

General Procedures. All reactions requiring a dry anoxic atmosphere were performed in glassware flame-dried or dried overnight in a $110{ }^{\circ} \mathrm{C}$ oven, covered with septa, and flushed with $\mathrm{N}_{2}$. Tetrahydrofuran (THF) and diethyl ether (ether) were freshly distilled under $\mathrm{N}_{2}$ from sodium benzophenone ketyl. Dimethyl ether $\left(\mathrm{Me}_{2} \mathrm{O}, \mathrm{bp}-24.8^{\circ} \mathrm{C}\right)$ was handled by condensation from a pressurized gas cylinder into a graduated conical tube cooled to $-78{ }^{\circ} \mathrm{C}$, dried with $n$-BuLi, and then condensed via a cannula into the desired vessel cooled to $-78^{\circ} \mathrm{C} . N, N$-Dimethylethylamine, $N, N, N^{\prime}, N^{\prime}$-tetramethylethylenediamine (TMEDA) and $N, N, N^{\prime}, N^{\prime \prime}, N^{\prime \prime}$-pentamethyldiethylenetetraamine (PMDTA) were distilled from $\mathrm{CaH}_{2}$ and stored under $\mathrm{N}_{2}$ over $4 \AA$ molecular sieves. $n$-BuLi was handled by syringe-based techniques. ${ }^{[20]}$

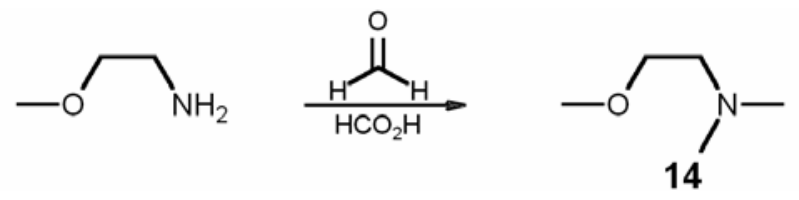

$N, N$-Dimethyl-2-methoxyethylamine (14). To a $500 \mathrm{~mL}$ round-bottom flask equipped with a stir bar and a dropping funnel was added 2-methoxyethylamine $(56 \mathrm{~mL}, 0.64 \mathrm{~mol})$. The flask was 
cooled to $0{ }^{\circ} \mathrm{C}$ and formic acid $(120 \mathrm{~mL}, 2.30 \mathrm{~mol}, 3.59$ equiv) was added to the amine via a dropping funnel at a rate of 1 drop/sec. To the acidic yellow solution, $140 \mathrm{~mL}$ of $37 \%$ aqueous formaldehyde (1.72 mol, 2.69 equiv) was added at a rate of 1 drop/sec. Rapid gas evolution was initiated upon heating the solution gradually to $60{ }^{\circ} \mathrm{C}$. The heating bath was removed until the gas evolution subsided $2 \mathrm{~h}$ later. The solution was then heated to $80{ }^{\circ} \mathrm{C}$ for $23 \mathrm{~h}$, cooled to $0{ }^{\circ} \mathrm{C}$, divided into $100 \mathrm{~mL}$ portions, and each basified to $\mathrm{pH} 9$ with $\mathrm{NaOH}$ pellets. Each $100 \mathrm{~mL}$ portion was extracted with ether $(3 \times 100 \mathrm{~mL})$. The ether extracts were each washed with brine $(100 \mathrm{~mL})$ and then combined. The ether was removed by simple distillation. The crude product was dried over $\mathrm{KOH}$ pellets and purified by a fractional distillation, keeping the fraction at 95$97{ }^{\circ} \mathrm{C}$, to yield $30.2 \mathrm{~g}(0.29 \mathrm{~mol}, 45 \%)$ of a clear, colorless liquid. The product was then distilled from $\mathrm{CaH}_{2}$ under $\mathrm{N}_{2}$ to yield $29.1 \mathrm{~g}(0.28 \mathrm{~mol}, 44 \%)$. Density $=0.81 \mathrm{~g} / \mathrm{mL}$. ${ }^{1} \mathrm{H}$ NMR $(300 \mathrm{MHz}$, $\left.\mathrm{CDCl}_{3}\right): \delta 2.27(\mathrm{~s}, 6 \mathrm{H}), 2.49(\mathrm{t}, J=5.89 \mathrm{~Hz}, 2 \mathrm{H}), 3.46(\mathrm{~s}, 3 \mathrm{H}), 3.47(\mathrm{t}, J=5.88 \mathrm{~Hz}, 2 \mathrm{H}) .{ }^{13} \mathrm{C}\left\{{ }^{1} \mathrm{H}\right\}$ NMR (75.4 MHz, $\left.\mathrm{CDCl}_{3}\right): \delta 45.54\left(\mathrm{CH}_{3}\right), 58.58\left(\mathrm{CH}_{3}\right), 58.63\left(\mathrm{CH}_{2}\right), 70.30\left(\mathrm{CH}_{2}\right)$. HRMS (EI): $\mathrm{M}^{+}=103.0990$ (calc. for $\mathrm{C}_{5} \mathrm{H}_{13} \mathrm{NO}=103.0997$ ).
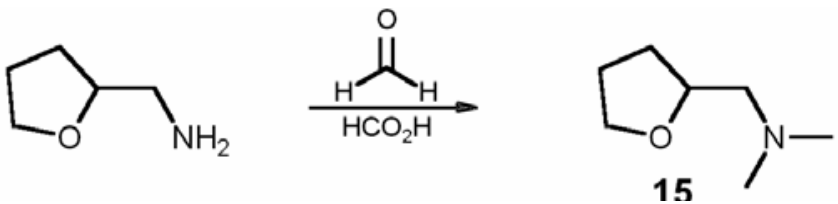

$N, N$-Dimethyltetrahydrofurfurylamine (15). Prepared by the same procedure as above, using tetrahydrofurfurylamine $(67 \mathrm{~mL}, 0.65 \mathrm{~mol})$, formic acid $(120 \mathrm{~mL}, 2.30 \mathrm{~mol}, 3.53$ equiv) and $150 \mathrm{~mL}$ of $37 \%$ aqueous formaldehyde (1.85 mol, 2.85 equiv). The product was purified by fractional distillation under $\mathrm{N}_{2}$, keeping the fraction at $149-153{ }^{\circ} \mathrm{C}$, to yield $17.4 \mathrm{~g}(135 \mathrm{mmol}$, $21 \%$ ) of a clear, colorless, pungent liquid. Density $=0.89 \mathrm{~g} / \mathrm{mL} .{ }^{1} \mathrm{H} \mathrm{NMR}\left(300 \mathrm{MHz}, \mathrm{CDCl}_{3}\right): \delta$ $1.50(\mathrm{dq}, J=11.8,8.1 \mathrm{~Hz}, 1 \mathrm{H}), 1.77-1.93(\mathrm{~m}, 2 \mathrm{H}), 1.94-2.07(\mathrm{~m}, 1 \mathrm{H}), 2.28(\mathrm{~s}, 6 \mathrm{H}), 2.29$ (dd, $J$ $=12.5,4.6 \mathrm{~Hz}, 1 \mathrm{H}), 2.43(\mathrm{dd}, J=12.5,8.5 \mathrm{~Hz}, 1 \mathrm{H}), 3.74(\mathrm{dt}, J=8.5,7.0 \mathrm{~Hz}, 1 \mathrm{H}), 3.87(\mathrm{dt}, J=$ 8.5, $7.5 \mathrm{~Hz}, 1 \mathrm{H}), 3.99(\mathrm{ddd}, J=11.8,7.5,4.6 \mathrm{~Hz}, 1 \mathrm{H}) .{ }^{13} \mathrm{C}\left\{{ }^{1} \mathrm{H}\right\} \mathrm{NMR}\left(75.4 \mathrm{MHz}, \mathrm{CDCl}_{3}\right): \delta$ $25.27\left(\mathrm{CH}_{2}\right), 29.98\left(\mathrm{CH}_{2}\right), 45.93\left(\mathrm{CH}_{3}\right), 64.14\left(\mathrm{CH}_{2}\right), 67.72\left(\mathrm{CH}_{2}\right), 76.79(\mathrm{CH})$. HRMS (EI): ${ }^{+}$ $=129.1150$ (calc. for $\mathrm{C}_{7} \mathrm{H}_{15} \mathrm{NO}=129.1154$ ).

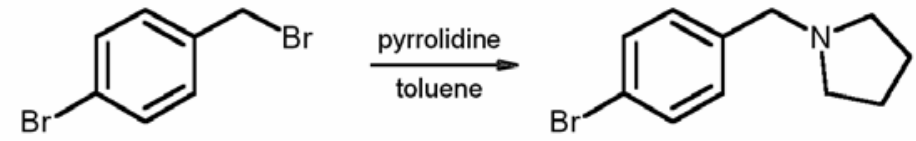

para-Bromobenzylpyrrolidine. ${ }^{[22]}$ para-Bromobenzyl bromide $(7.78 \mathrm{~g}, 31.1 \mathrm{mmol})$ and $6.0 \mathrm{~mL}$ of pyrrolidine ( $71.9 \mathrm{mmol}, 2.31$ equiv) were dissolved in $25 \mathrm{~mL}$ of toluene. Since pyrrolidine and toluene are not miscible, the reaction mixture was stirred vigorously overnight. The reaction mixture was taken up in 1:1 ether/hexanes $(40 \mathrm{~mL})$, washed with saturated aqueous $\mathrm{Na}_{2} \mathrm{CO}_{3}$ $(200 \mathrm{~mL})$, distilled water $(200 \mathrm{~mL})$, and brine $(100 \mathrm{~mL})$, dried over $\mathrm{MgSO}_{4}$, filtered, and concentrated in vacuo to give a clear, colorless oil. The crude product was purified by a 
Kugelrohr distillation $\left(110-120{ }^{\circ} \mathrm{C} / 0.06 \mathrm{~mm} \mathrm{Hg}\right)$ to yield $6.95 \mathrm{~g}(28.9 \mathrm{mmol}, 93 \%)$ of a clear, colorless oil. ${ }^{1} \mathrm{H}$ NMR (300 MHz, $\left.\mathrm{CDCl}_{3}\right): \delta 1.70-1.84(\mathrm{~m}, 4 \mathrm{H}), 2.40-2.54(\mathrm{~m}, 4 \mathrm{H}), 3.54(\mathrm{~s}, 2 \mathrm{H})$, 7.17-7.23 and 7.39-7.44 (AA'BB', 4H). ${ }^{13} \mathrm{C}\left\{{ }^{1} \mathrm{H}\right\}$ NMR (75.4 MHz, $\left.\mathrm{CDCl}_{3}\right): \delta 23.38\left(\mathrm{CH}_{2}\right)$, $54.02\left(\mathrm{CH}_{2}\right), 59.87\left(\mathrm{CH}_{2}\right), 120.53(\mathrm{C}), 130.41(\mathrm{CH}), 131.18(\mathrm{CH}), 138.38(\mathrm{C})$. HRMS $(\mathrm{EI}): \mathrm{M}^{+}=$ 241.0270 (calc. for $\mathrm{C}_{11} \mathrm{H}_{14} \mathrm{Br}=241.0290$ ).

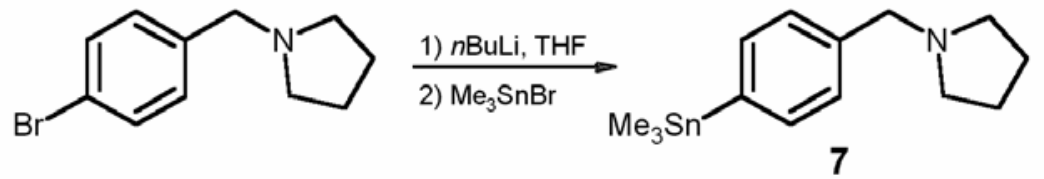

para-Trimethylstannylbenzylpyrrolidine (7). para-Bromobenzylpyrrolidine $\quad(2.23 \quad \mathrm{~g}$, $9.29 \mathrm{mmol}$ ) and $20 \mathrm{~mL}$ of THF were added to a dried and $\mathrm{N}_{2}$-flushed $50 \mathrm{~mL}$ round-bottom flask fitted with a septum. The flask was cooled to $-78{ }^{\circ} \mathrm{C}$ under positive $\mathrm{N}_{2}$ pressure and $2.70 \mathrm{~mL}$ of $3.79 \mathrm{M} n$-BuLi in hexanes (10.23 mmol, 1.10 equiv) was added. The solution was a greenishyellow color. After stirring at $-78^{\circ} \mathrm{C}$ for $3 \mathrm{~min}$, the lithium reagent was quenched by the addition of $2.49 \mathrm{~g}$ of $\mathrm{Me}_{3} \mathrm{SnBr}$ (10.24 mmol, 1.10 equiv) in $7 \mathrm{~mL}$ of THF. The solution was taken up in 1:1 ether/hexanes $(40 \mathrm{~mL})$, washed with distilled water $(2 \times 200 \mathrm{~mL})$ and brine $(100 \mathrm{~mL})$. The organic fraction was dried over $\mathrm{MgSO}_{4}$, filtered, and concentrated in vacuo to give 7 as a clear, pale yellow oil. The crude product was purified by a Kugelrohr distillation (125-140 $\left.{ }^{\circ} \mathrm{C} / 0.05 \mathrm{~mm} \mathrm{Hg}\right)$ to yield $1.96 \mathrm{~g}(6.06 \mathrm{mmol}, 65 \%)$ of a clear, colorless oil. Density $=1.25 \mathrm{~g} / \mathrm{mL}$. ${ }^{1} \mathrm{H}$ NMR $\left(300 \mathrm{MHz}, \mathrm{CDCl}_{3}\right): \delta 0.28\left(\mathrm{~s},{ }^{2} J_{119 \mathrm{Sn}-\mathrm{H}}=53.0 \mathrm{~Hz}, 9 \mathrm{H}\right), 1.73-1.84(\mathrm{~m}, 4 \mathrm{H}), 2.46-2.55$ $(\mathrm{m}, 4 \mathrm{H}), 3.60(\mathrm{~s}, 2 \mathrm{H}), 7.27-7.35$ and $7.35-7.54\left(\mathrm{AA}^{\prime} \mathrm{BB}^{\prime}, 4 \mathrm{H}\right) .{ }^{13} \mathrm{C}\left\{{ }^{1} \mathrm{H}\right\} \mathrm{NMR}(75.4 \mathrm{MHz}$, $\left.\mathrm{CDCl}_{3}\right): \delta-9.58\left(\mathrm{CH}_{3},{ }^{1} J_{119 \mathrm{Sn}-13 \mathrm{C}}=350.3 \mathrm{~Hz}\right), 23.42\left(\mathrm{CH}_{2}\right), 54.14\left(\mathrm{CH}_{2}\right), 60.67\left(\mathrm{CH}_{2}\right), 128.63(\mathrm{CH}$, $\left.{ }^{2} J_{11_{\mathrm{Sn}-}{ }^{13 \mathrm{C}}}=46.4 \mathrm{~Hz}\right), 135.70\left(\mathrm{CH},{ }^{3} J_{119 \mathrm{Sn}-13 \mathrm{C}}=36.9 \mathrm{~Hz}\right), 139.33\left(\mathrm{C},{ }^{4} J_{119 \mathrm{Sn}-13 \mathrm{C}}=10.2 \mathrm{~Hz}\right) .{ }^{119} \mathrm{Sn}\left\{{ }^{1} \mathrm{H}\right\}$ NMR (THF, $134.3 \mathrm{MHz},-78{ }^{\circ} \mathrm{C}$ ): $\delta-30.3$. HRMS (EI): $\mathrm{M}^{+}: 325.0858$; calc. for $\mathrm{C}_{14} \mathrm{H}_{23} \mathrm{NSn}$ : 325.0851 .
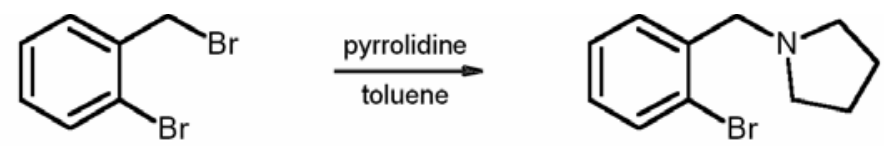

ortho-Bromobenzylpyrrolidine (8). ${ }^{[23]}$ ortho-Bromobenzyl bromide (5.89 g, $\left.23.6 \mathrm{mmol}\right)$, $5.0 \mathrm{~mL}$ of pyrrolidine (59.8 mmol, 2.54 equiv), and $30 \mathrm{~mL}$ of toluene were reacted as for the para-isomer 7. The crude product was purified by a Kugelrohr distillation $\left(103-115{ }^{\circ} \mathrm{C} / 0.02 \mathrm{~mm}\right.$ $\mathrm{Hg}$ ) to yield $4.96 \mathrm{~g}$ of a clear colorless oil (20.7 mmol, 89\%). Density $=1.32 \mathrm{~g} / \mathrm{mL}$. ${ }^{1} \mathrm{H}$ NMR $\left(\mathrm{CDCl}_{3}, 300 \mathrm{MHz}\right): \delta$ 1.74-1.87 (m, 4H), 2.57-2.66 (m, 4H), $3.76(\mathrm{~s}, 2 \mathrm{H}), 7.05-7.12(\mathrm{~m}, 1 \mathrm{H})$, $7.28(\mathrm{td}, J=7.54,1.29 \mathrm{~Hz}, 1 \mathrm{H}), 7.48-7.55(\mathrm{~m}, 2 \mathrm{H}) .{ }^{13} \mathrm{C}\left\{{ }^{1} \mathrm{H}\right\} \mathrm{NMR}\left(\mathrm{CDCl}_{3}, 75.4 \mathrm{MHz}\right): \delta 23.55$ $\left(\mathrm{CH}_{2}\right), 54.14\left(\mathrm{CH}_{2}\right), 59.45\left(\mathrm{CH}_{2}\right), 124.10(\mathrm{C}), 127.22(\mathrm{CH}), 128.16(\mathrm{CH}), 130.51(\mathrm{CH}), 132.52$ (CH), 138.45 (C). HRMS (EI): $\mathrm{M}^{+}=241.0290$ (calc. for $\mathrm{C}_{11} \mathrm{H}_{14} \mathrm{BrN}=241.0290$ ). 


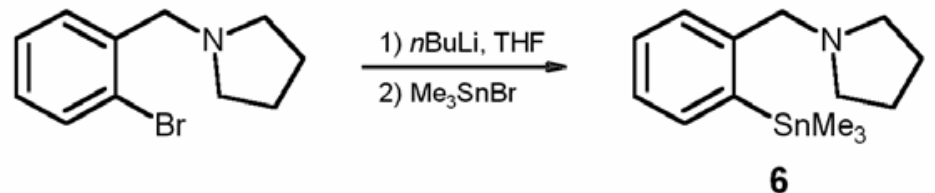

ortho-Trimethylstannylbenzylpyrrolidine (6). ortho-Bromobenzylpyrrolidine (8, $1.72 \mathrm{~g}$, $7.16 \mathrm{mmol}$ ) and $15 \mathrm{~mL}$ of THF were added to a dried and $\mathrm{N}_{2}$-flushed $50 \mathrm{~mL}$ round-bottom flask fitted with a septum. The flask was cooled to $-78{ }^{\circ} \mathrm{C}$ under positive $\mathrm{N}_{2}$ pressure, then $2.40 \mathrm{~mL}$ of $3.03 \mathrm{M} \mathrm{n}$-BuLi in hexanes (7.27 mmol, 1.02 equiv) was added. The solution was initially a clear, amber color but became heterogenous within 5 minutes. The lithium reagent was quenched by the addition of $1.90 \mathrm{~g}$ of $\mathrm{Me}_{3} \mathrm{SnBr}$ (10.64 mmol, 1.04 equiv) in $5 \mathrm{~mL}$ of THF. The solution was taken up in 1:1 ether/hexanes $(40 \mathrm{~mL})$, washed with distilled water $(2 \times 250 \mathrm{~mL})$ and brine $(100 \mathrm{~mL})$. The organic fraction was dried over $\mathrm{MgSO}_{4}$, filtered, and concentrated in vacuo to give 6 as a clear, yellow oil. The crude product was purified by a Kugelrohr distillation (112$\left.120^{\circ} \mathrm{C} / 0.02 \mathrm{~mm} \mathrm{Hg}\right)$ to yield $2.054 \mathrm{~g}(6.34 \mathrm{mmol}, 89 \%)$ of a clear, colorless oil. Density = $1.27 \mathrm{~g} / \mathrm{mL} .{ }^{1} \mathrm{H}$ NMR $\left(\mathrm{CDCl}_{3}, 300 \mathrm{MHz}\right): \delta 0.22\left(\mathrm{~s},{ }^{2} J_{119 \mathrm{Sn}-\mathrm{H}}=54.0 \mathrm{~Hz}, 9 \mathrm{H}\right), 1.67-1.84(\mathrm{~m}, 4 \mathrm{H})$, 2.36-2.47 (m, 4H), $3.58(\mathrm{~s}, 2 \mathrm{H}), 7.11-7.27(\mathrm{~m}, 3 \mathrm{H}), 7.42-7.65(\mathrm{~m}, 1 \mathrm{H}) .{ }^{13} \mathrm{C}\left\{{ }^{1} \mathrm{H}\right\} \mathrm{NMR}\left(\mathrm{CDCl}_{3}\right.$, $75.4 \mathrm{MHz}): \delta-7.57\left(\mathrm{CH}_{3}\right), 23.53\left(\mathrm{CH}_{2}\right), 54.05\left(\mathrm{CH}_{2}\right), 63.32\left(\mathrm{CH}_{2}\right), 126.46(\mathrm{CH}), 128.03(\mathrm{CH})$, $128.08(\mathrm{CH}), 136.69(\mathrm{CH}), 142.66(\mathrm{C}), 146.27(\mathrm{C})$. HRMS (EI): $\mathrm{M}^{+}=310.0620$ (calc. for $\left.\mathrm{C}_{14} \mathrm{H}_{23} \mathrm{NSn}-\mathrm{CH}_{3}=310.0617\right)$.

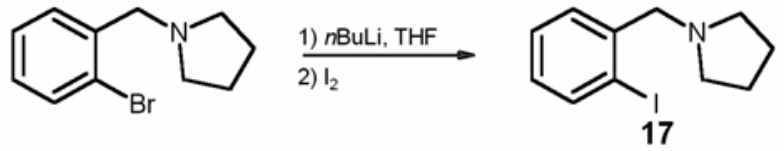

ortho-Iodobenzylpyrrolidine $(\mathbf{1 7}) .{ }^{[24]}$ ortho-Bromobenzylpyrrolidine $(1.13 \mathrm{~g}, 4.72 \mathrm{mmol})$ in $15 \mathrm{~mL}$ of THF was metalated with $1.70 \mathrm{~mL}$ of $2.87 \mathrm{M} n$-BuLi in hexanes (4.88 mmol, 1.03 equiv) as for the preparation of 6. Elemental iodine ( $1.35 \mathrm{~g}, 5.32 \mathrm{mmol}, 1.13$ equiv) in $5 \mathrm{~mL}$ of THF was added. The reaction mixture was taken up in $1: 1$ ether/hexanes $(40 \mathrm{~mL})$, washed with $10 \% \mathrm{Na}_{2} \mathrm{~S}_{2} \mathrm{O}_{3}(200 \mathrm{~mL})$, distilled water $(200 \mathrm{~mL})$ and brine $(100 \mathrm{~mL})$. The organic fraction was dried over $\mathrm{MgSO}_{4}$, filtered, and concentrated in vacuo to give a clear, yellow oil. The crude product was purified by a Kugelrohr distillation $\left(121-130{ }^{\circ} \mathrm{C} / 0.03-0.04 \mathrm{~mm} \mathrm{Hg}\right.$ ) to yield $0.977 \mathrm{~g}$ (3.40 mmol, 72\%) of $\mathbf{1 7}$ as a clear, colorless oil. Density $=1.52 \mathrm{~g} / \mathrm{mL} .{ }^{1} \mathrm{H}$ NMR $\left(\mathrm{CDCl}_{3}\right.$, $300 \mathrm{MHz}): \delta 1.74-1.85(\mathrm{~m}, 4 \mathrm{H}), 2.47-2.64(\mathrm{~m}, 4 \mathrm{H}), 3.67(\mathrm{~s}, 2 \mathrm{H}), 6.92(\mathrm{ddd}, J=7.72,7.35$, $1.29 \mathrm{~Hz}, 1 \mathrm{H}), 7.31(\mathrm{td}, J=7.35,1.10 \mathrm{~Hz}, 1 \mathrm{H}), 7.43(\mathrm{dd}, J=7.72,1.84 \mathrm{~Hz}, 1 \mathrm{H}), 7.82(\mathrm{dd}, J=$ 7.72, $1.10 \mathrm{~Hz}, 1 \mathrm{H}) .{ }^{13} \mathrm{C}\left\{{ }^{1} \mathrm{H}\right\} \mathrm{NMR}\left(\mathrm{CDCl}_{3}, 75.4 \mathrm{MHz}\right): \delta 23.66\left(\mathrm{CH}_{2}\right), 54.12\left(\mathrm{CH}_{2}\right), 64.40$ $\left(\mathrm{CH}_{2}\right), 100.08(\mathrm{C}), 128.06(\mathrm{CH}), 128.42(\mathrm{CH}), 129.91(\mathrm{CH}), 139.24(\mathrm{CH}), 141.65(\mathrm{C}) . \mathrm{HRMS}$ (EI): $\mathrm{M}^{+}=287.0156$ (calc. for $\mathrm{C}_{11} \mathrm{H}_{14} \mathrm{IN}=287.0173$ ).

Low-temperature multinuclear NMR spectroscopy. All low-temperature multinuclear NMR experiments were conducted on a Bruker AM-360 or AVANCE spectrometer equipped with a $10 \mathrm{~mm}$ wide-bore broadband probe at the following frequencies: $360.148 \mathrm{MHz}\left({ }^{1} \mathrm{H}\right)$, $90.556 \mathrm{MHz}\left({ }^{13} \mathrm{C}\right), 52.984 \mathrm{MHz}\left({ }^{6} \mathrm{Li}\right), 139.905 \mathrm{MHz}\left({ }^{7} \mathrm{Li}\right)$, and $134.348 \mathrm{MHz}\left({ }^{119} \mathrm{Sn}\right)$. The digital resolution was $0.15 \mathrm{~Hz}$ for ${ }^{1} \mathrm{H}, 0.6-1.2 \mathrm{~Hz}$ for ${ }^{13} \mathrm{C}, 0.2-0.8 \mathrm{~Hz}$ for ${ }^{6} \mathrm{Li}, 0.5-1.0 \mathrm{~Hz}$ for ${ }^{7} \mathrm{Li}$, and $0.6-$ 


\section{$1.2 \mathrm{~Hz}$ for ${ }^{31} \mathrm{P}$.}

All spectra were taken of samples in a combination of the protio solvents THF, ether, and/or $\mathrm{Me}_{2} \mathrm{O}$ with the spectrometer unlocked. This combination of solvents is close to the donor strength of pure THF and allowed the measurement of spectra down to $-160{ }^{\circ} \mathrm{C}$ without sample freezing. ${ }^{13} \mathrm{C}$ spectra were acquired with standard composite pulse decoupling (CPD), distortionless enhancement by polarization transfer (DEPT) and/or quaternary-only decoupled (QUATD) pulse sequences, and referenced internally to the C-2 carbon of THF ( $\delta 67.96)$, the C2 carbon of ether $(\delta 66.57)$, or the $\mathrm{C}-1$ carbon of $\mathrm{Me}_{2} \mathrm{O}(\delta 60.25)$. Lorenzian multiplication (LB) was applied to ${ }^{13} \mathrm{C}$ FIDs. ${ }^{6} \mathrm{Li}$ and ${ }^{7} \mathrm{Li}$ spectra were referenced externally to $0.3 \mathrm{M} \mathrm{LiCl} / \mathrm{MeOH}(\delta$ $0.00)$ or internally to $\mathrm{Li}^{+}(\mathrm{HMPA})_{4}(\delta-0.40) .{ }^{31} \mathrm{P}$ spectra were referenced externally to $1.0 \mathrm{M}$ $\mathrm{PPh}_{3} / \mathrm{THF}(\delta-6.00)$ or internally to free HMPA $(\delta 26.40)$. Gaussian multiplication $(\mathrm{GM})$ was applied to ${ }^{6} \mathrm{Li}$, ${ }^{7} \mathrm{Li}$ and ${ }^{31} \mathrm{P}$ spectra, where the Gaussian broadening parameter (GB) was equal to the duration of the free induction decay (FID) and the Lorenzian broadening parameter was equal to the negative of digital resolution/GB.

General procedure for NMR spectroscopy of organolithium reagents. Samples of organolithium reagents $(0.5 \mathrm{mmol}$ in $3 \mathrm{~mL}$ of solvent $)$ were prepared in thin-walled $10 \mathrm{~mm}$ NMR tubes that were oven-dried overnight, fitted with $9 \mathrm{~mm}$ i.d. septa, and flushed with $\mathrm{N}_{2}$. Silicon grease was applied to the interface between the tube and the septa before securing with parafilm for a better seal, as well as to the top of the septa to seal needle punctures. Samples were stored at $78{ }^{\circ} \mathrm{C}$ until the experiment was performed. After adjustment of the shim values for the $\mathrm{CDCl}_{3}$ lock sample, the spectrometer was unlocked, the sweep was turned off, and the probe was cooled initially to $-120{ }^{\circ} \mathrm{C}$. The sample was shimmed on the ${ }^{13} \mathrm{C}$ FID of the C-O carbons of THF, or $\mathrm{Me}_{2} \mathrm{O}$. Spectra of appropriate NMR nuclei (which usually included ${ }^{13} \mathrm{C},{ }^{6} \mathrm{Li}$ and ${ }^{7} \mathrm{Li}$ ) were measured. If the sample was pure, a cosolvent titration or variable temperature (VT) experiment could be performed. In the case of a titration experiment, the sample was ejected, placed in a $78{ }^{\circ} \mathrm{C}$ bath, the silicon grease was removed from the top of the septum, a desired amount of cosolvent was added, silicon grease was reapplied to the top of the septum, the sample was returned to the cooled NMR probe, and the desired NMR spectra were measured. This process was repeated for subsequent additions of cosolvent. In the case of a VT experiment, probe temperatures were measured externally by ejecting the sample and inserting a thermocouple into the probe or internally with a ${ }^{13} \mathrm{C}$ chemical-shift thermometer. ${ }^{[7 \mathrm{e}]}$

The use of $10 \mathrm{~mm}$ NMR tubes provided a real advantage over $5 \mathrm{~mm}$ tubes because of the approximate three-fold signal to noise enhancement with more sample in the magnetic field, more accurate additions of cosolvents, and minimal sample warming when transferring tubes from the $-78^{\circ} \mathrm{C}$ bath to the NMR probe.

General procedure for preparation of aryllithium reagents for NMR spectroscopy. The aryltrimethylstannane was added to a dried and $\mathrm{N}_{2}$-flushed $10 \mathrm{~mm}$ NMR tube. The tube was cooled to $-78{ }^{\circ} \mathrm{C}$ and $1 \mathrm{~mL}$ of $\mathrm{Me}_{2} \mathrm{O}$ (or diethyl ether, when noted) was condensed into it. The 
NMR tube was temporarily removed from the $-78{ }^{\circ} \mathrm{C}$ bath, warmed slightly, and shaken repeatedly to dissolve the arylstannane. The addition of 1.0 equiv of $n$ - $\mathrm{Bu}^{6} \mathrm{Li}$ to the NMR tube gave a homogenous yellow solution. The NMR tube was stored overnight at $-78{ }^{\circ} \mathrm{C}$ while the aryllithium reagent crystallized out of solution. The yellow supernatant was removed by cannula transfer and the crystals were washed with ether $(2 \times 0.5 \mathrm{~mL})$ at $-78{ }^{\circ} \mathrm{C}$. The crystals were dissolved in a combination of THF and ether, by both warming the solvent mixture to room temperature and vigorously shaking the NMR tube, to give a clear, colorless solution of aryllithium reagent with concentrations ranging from 0.08 to $0.16 \mathrm{M}$. The NMR tube was returned to the $-78{ }^{\circ} \mathrm{C}$ bath, and $\mathrm{Me}_{2} \mathrm{O}$ was added if needed. The sample was ready for NMR investigation.

Variable-concentration ${ }^{13} \mathrm{C}$ and ${ }^{6} \mathrm{Li}$ NMR experiment of ${ }^{6} \mathrm{Li}$-labeled 5 . A solution of 7 (95 mg, $0.292 \mathrm{mmol})$ in THF $(3.0 \mathrm{~mL})$ was prepared in a dried and $\mathrm{N}_{2}$-flushed $10 \mathrm{~mm} \mathrm{NMR}$ tube. The NMR tube was cooled to $-78^{\circ} \mathrm{C}$. The addition of $0.79 \mathrm{M} n \mathrm{Bu}{ }^{6} \mathrm{Li}$ in hexanes $(0.37 \mathrm{~mL}$, $0.29 \mathrm{mmol}, 1.00$ equiv) to the NMR tube gave a yellow solution with an initial concentration of $0.087 \mathrm{M}$ 5. The variable concentration experiment was monitored by ${ }^{13} \mathrm{C}$ and ${ }^{6} \mathrm{Li} \mathrm{NMR}$ spectroscopy. The DEPT-90 pulse sequence was used to acquire the ${ }^{13} \mathrm{C}$ NMR spectra. The ${ }^{13} \mathrm{C}$ and ${ }^{6} \mathrm{Li} \mathrm{NMR}$ spectra were acquired at aryllithium concentrations of $0.087,0.060,0.046$, and $0.031 \mathrm{M}$ by the addition of THF $(1.20 \mathrm{~mL})$ and of ether $(0.80 \mathrm{~mL})$ at each point in the experiment. The ortho carbons of the monomeric and dimeric species were integrated by simulation using WinDNMR. ${ }^{[7]}$ Spectra are shown in Figure 4, data in Table 1. After the experiment was completed, the sample was quenched with $\mathrm{Me}_{3} \mathrm{SiCl}(100 \mu \mathrm{L}, 0.788 \mathrm{mmol}, 2.70$ equiv) to give a $64 \%$ yield of $N$-(para-trimethylsilylbenzyl)pyrrolidine by ${ }^{1} \mathrm{H}$ NMR against pentachloroethane $(10.0 \mu \mathrm{L}, 0.083 \mathrm{mmol}, 0.284$ equiv) as a standard.

Table 1. Data from the variable concentration experiment

\begin{tabular}{llllll}
\hline Total $[\mathrm{ArLi}]$ & {$\left[(\mathrm{ArLi})_{2}\right]$} & {$\left[(\mathrm{ArLi})_{1}\right]$} & $\mathrm{Keq}$ & $\log \left[(\mathrm{ArLi})_{2}\right]$ & $\left.\log (\mathrm{ArLi})_{1}\right]$ \\
\hline 0.087 & 0.034 & 0.019 & 91 & -1.47 & -1.71 \\
0.060 & 0.021 & 0.017 & 73 & -1.67 & -1.77 \\
0.046 & 0.015 & 0.015 & 69 & -1.81 & -1.82 \\
0.031 & 0.0096 & 0.012 & 67 & -2.02 & -1.92 \\
\hline
\end{tabular}

Variable-temperature ${ }^{13} \mathrm{C}$ and ${ }^{6} \mathrm{Li}$ NMR experiment on 5. A pure sample of $\mathbf{5}$ was prepared by the general procedure for the crystallization and purification of aryllithium reagents for NMR, using 7, (100 mg, $0.31 \mathrm{mmol}), 3.0 \mathrm{~mL}$ of THF, $4 \mu \mathrm{L}$ of ${ }^{13} \mathrm{C}$ chemical-shift thermometer ${ }^{[7 \mathrm{e}]}$ and $0.39 \mathrm{~mL}$ of $0.79 \mathrm{M} \mathrm{n}$-Bu $\mathrm{Li}^{6}$ in hexanes $(0.31 \mathrm{mmol}, 1.0$ equiv). The initial concentration of 5 was $0.09 \mathrm{M}$. The variable temperature experiment was monitored by ${ }^{13} \mathrm{C}$ and ${ }^{6} \mathrm{Li} \mathrm{NMR}$ spectroscopy with spectra acquired at the following sample temperatures: $-122,-114,-112,-105$, $-100,-93,-87,-84,-68$ and $-53{ }^{\circ} \mathrm{C}$. Spectra were simulated using the 2 -site mutual exchange setting in WINDNMR, ${ }^{[7 \mathrm{~d}]}$ and are shown in Figure 5.

After the variable temperature experiment was completed, a PMDTA titration was performed on 
the sample.

PMDTA titration of ${ }^{6} \mathbf{L i}$-labeled 5. A PMDTA titration of the ${ }^{6} \mathrm{Li}$-labeled $\mathbf{5}$ was conducted on the $0.09 \mathrm{M}$ sample used prior for the variable-temperature experiment. The PMDTA titration experiment was monitored by ${ }^{6} \mathrm{Li}$ NMR spectroscopy with spectra acquired at $0,0.25,0.5,0.75$, 1 and 1.5 equiv of PMDTA $(1$ equiv $=64 \mu \mathrm{L})$. The probe temperature was $-120^{\circ} \mathrm{C}$ during the experiment. After the experiment was completed, the sample was quenched with $\mathrm{Me}_{3} \mathrm{SiCl}$ (100 $\mu \mathrm{L} 0.79 \mathrm{mmol}, 2.56$ equiv) to give a $96 \%$ yield of $N$-(para-trimethylsilylbenzyl)pyrrolidine by ${ }^{1} \mathrm{H}$ NMR against pentachloroethane $(18.0 \mu \mathrm{L}, 0.150 \mathrm{mmol}, 0.49$ equiv $)$ as a standard. Spectra are shown in Figure 9.

TMEDA titration of ${ }^{6} \mathbf{L i}$-labeled 5 in THF. A $0.09 \mathrm{M}$ solution of $\mathbf{5}$ in THF (3 mL) was prepared from 7 (95 mg, $0.29 \mathrm{mmol})$ and $0.79 \mathrm{M} \mathrm{n}$-Bu ${ }^{6} \mathrm{Li}$ in hexanes $(0.37 \mathrm{~mL}, 0.29 \mathrm{mmol}, 0.99$ equiv). The TMEDA titration experiment was monitored by ${ }^{6} \mathrm{Li} \mathrm{NMR}$ spectroscopy. The ${ }^{6} \mathrm{Li}$ NMR spectra were acquired at $0,0.5,1,2,4,6$ and 8 equiv of TMEDA ( 1 equiv $=44 \mu \mathrm{L})$. The probe temperature was $-120^{\circ} \mathrm{C}$ during the experiment. After the experiment was completed, the sample was quenched with $\mathrm{Me}_{3} \mathrm{SiCl}(100 \mu \mathrm{L}, 0.79 \mathrm{mmol}, 2.7$ equiv) to give a $84 \%$ yield of $N$ (para-trimethylsilylbenzyl)pyrrolidine by ${ }^{1} \mathrm{H}$ NMR against pentachloroethane $(15.0 \mu \mathrm{L}$, $0.125 \mathrm{mmol}, 0.425$ equiv) as a standard. Spectra are shown in Figure 8a.

Amine titrations of ${ }^{6} \mathbf{L i}$-labeled 5 THF/ $\mathbf{M e}_{2} \mathrm{O} /$ ether. A solution of 7 (97 $\left.\mathrm{mg}, 0.30 \mathrm{mmol}\right)$ in THF $(1.5 \mathrm{~mL})$ and ether $(0.5 \mathrm{~mL})$ was prepared in a dried and $\mathrm{N}_{2}$-flushed $10 \mathrm{~mm}$ NMR tube. The tube was cooled to $-78{ }^{\circ} \mathrm{C}$ and $0.79 \mathrm{M} \mathrm{n}$-Bu ${ }^{6} \mathrm{Li}$ in hexanes $(0.38 \mathrm{~mL}, 0.30 \mathrm{mmol}, 1.01$ equiv) was added to give a yellow solution. The addition of $\mathrm{Me}_{2} \mathrm{O}(1.0 \mathrm{~mL})$ gave an initial aryllithium concentration of $0.09 \mathrm{M}$. The TMEDA titration experiment was monitored by ${ }^{6} \mathrm{Li}$ NMR spectroscopy. The ${ }^{6} \mathrm{Li}$ NMR spectra were acquired at $0,0.5,1,1.5,2$ and 3 equiv of TMEDA (1 equiv $=45 \mu \mathrm{L}$ ). The probe temperature ranged from -130 to $-137{ }^{\circ} \mathrm{C}$ during the experiment. After the experiment was completed, the sample was quenched with $\mathrm{Me}_{3} \mathrm{SiCl}(100 \mu \mathrm{L}$, $0.788 \mathrm{mmol}, 2.64$ equiv) to give a $91 \%$ yield of $N$-(para-trimethylsilylbenzyl)pyrrolidine by ${ }^{1} \mathrm{H}$ NMR against pentachloroethane $(10.0 \mu \mathrm{L}, 0.083 \mathrm{mmol}, 0.425$ equiv) as a standard. Similar experiments were performed with $N, N$-dimethyl-2-methoxyethylamine (14), $N, N$-dimethyltetrahydrofurfurylamine (15) and dimethylethylamine. Spectra are shown in Figure 8b,c,d.

Variable-temperature ${ }^{13} \mathrm{C}$ NMR experiment on 4. A pure sample of 4 was prepared by crystallization from ether. A solution of $6(33 \mathrm{mg}, 1.03 \mathrm{mmol})$ in ether $(1.8 \mathrm{~mL})$ in a dried and $\mathrm{N}_{2}$-flushed $10 \mathrm{~mm}$ NMR tube was cooled to $-78^{\circ} \mathrm{C}$, and $1.54 \mathrm{M} n$-Bu ${ }^{6} \mathrm{Li}$ in hexanes $(0.67 \mathrm{~mL}$, $1.03 \mathrm{mmol}, 1.00$ equiv) was added. The sample was stored for $12 \mathrm{~h}$ at $-20{ }^{\circ} \mathrm{C}$ while the aryllithium reagent crystallized. The yellow supernatant was removed by cannula transfer, and the crystals were washed with ether $(2 \times 0.5 \mathrm{~mL})$. The aryllithium crystals were dissolved in THF $(1.8 \mathrm{~mL})$ and ether $(1.2 \mathrm{~mL})$ to give a clear, colorless $0.13 \mathrm{M}$ solution. The variable temperature experiment was monitored by ${ }^{13} \mathrm{C}$ NMR spectroscopy with spectra acquired at the following probe temperatures: $-123,-111,-99,-93,-87,-81,-75,-69,-63,-57,-51,-39,-27,-14,-2$, 10 and $22{ }^{\circ} \mathrm{C}$. Rate constants for intra and intermolecular exchange were determined by shape analysis of the ${ }^{13} \mathrm{C}$ signals for the pyrrolidine using 2-site mutual exchange and for the C-Li 
carbon using the quintet-tetramer exchange matrix of WinDNMR. ${ }^{[7 \mathrm{a}, 7 \mathrm{~d}]}$ Spectra and simulations are shown in Figure 12.

After the VT experiment was completed, a VT iodine "ate" complex experiment was performed on the sample.

TMEDA titration of ${ }^{6} \mathbf{L i}$-labeled 4. A pure sample of $\mathbf{4}$ was prepared by the general procedure for the crystallization and purification of aryllithium reagents for NMR using 6, (19.3 mg, $0.60 \mathrm{mmol})$ and $0.79 \mathrm{M} \mathrm{nBu}{ }^{6} \mathrm{Li}$ in hexanes $(0.79 \mathrm{~mL}, 0.62 \mathrm{mmol}, 1.05$ equiv). The aryllithium crystals were dissolved in THF $(1.8 \mathrm{~mL})$ and ether $(1.2 \mathrm{~mL})$ to give a clear, colorless $0.16 \mathrm{M}$ solution. The TMEDA titration experiment was monitored by ${ }^{13} \mathrm{C}$ and ${ }^{6} \mathrm{Li}$ NMR spectroscopy. The ${ }^{13} \mathrm{C}$ and ${ }^{6} \mathrm{Li}$ NMR spectra were acquired at $0,0.5,1,2,4$ and 10 equiv of TMEDA ( 1 equiv $=$ $90 \mu \mathrm{L})$. The probe temperature was $-125^{\circ} \mathrm{C}$ during the experiment. Spectra are shown in Figure 14. After the experiment was completed, the sample was quenched with $\mathrm{Me}_{3} \mathrm{SiCl}(200 \mu \mathrm{L}$, $1.58 \mathrm{mmol}, 2.65$ equiv) to give a $93 \%$ yield of $N$-(ortho-trimethylsilylbenzyl)pyrrolidine by ${ }^{1} \mathrm{H}$ NMR against pentachloroethane $(36 \mu \mathrm{L}, 0.30 \mathrm{mmol}, 0.50$ equiv) as a standard.

Table 2. Complexation of 4 with TMEDA in THF/ether $(3: 2)$ at $-135^{\circ} \mathrm{C}$

$$
(\mathbf{4})_{2}+\mathrm{TMEDA} \leftrightarrows(\mathbf{4})_{2} \bullet \mathrm{TMEDA} \quad \mathrm{K}_{\mathrm{eq}}=\left[(\mathbf{4})_{2} \bullet \mathrm{TMEDA}\right] /\left(\left[(\mathbf{4})_{2}\right][\mathrm{TMEDA}]\right)
$$

\begin{tabular}{llll}
\hline$[$ TMEDA $]$ & {$\left[(4)_{2}\right]$} & {$\left[(4)_{2} \bullet\right.$ TMEDA $]$} & Keq $(\mathrm{L} / \mathrm{mol})$ \\
\hline 0.373 & 0.072 & 0.0021 & 0.078 \\
0.702 & 0.065 & 0.0054 & 0.118 \\
1.529 & 0.057 & 0.0057 & 0.065 \\
\hline
\end{tabular}

Variable temperature study of $0.20 \mathrm{M} 4$ and $0.20 \mathrm{PhLi}$ in 3:2 THF/ether. A solution of 6 $(150 \mu \mathrm{L}, 0.59 \mathrm{mmol})$ in THF $(1.8 \mathrm{~mL})$ was added to a dried and $\mathrm{N}_{2}$-flushed $10 \mathrm{~mm}$ NMR tube. The tube was cooled to $-78^{\circ} \mathrm{C}$ and $2.55 \mathrm{M} n$-BuLi in hexanes $(0.24 \mathrm{~mL}, 0.60 \mathrm{mmol})$ was added to give a yellow solution. The addition of $0.50 \mathrm{M} \mathrm{PhLi}$ in ether $(1.2 \mathrm{~mL}, 0.60 \mathrm{mmol})$ gave an initial concentration of $0.20 \mathrm{M}$ for each lithium reagent. During the experiment ${ }^{13} \mathrm{C}$ and ${ }^{7} \mathrm{Li} \mathrm{NMR}$ spectra were acquired at $-127,-117,-106,-94,-87,-80,-71,-62,-58,-51,-46,-32,-27$, $-22,-15$, and $-8{ }^{\circ} \mathrm{C}$. Rate constants were determined by line shape analysis of the ${ }^{7} \mathrm{Li} \mathrm{NMR}$ spectra using the "AA'BC" exchange matrix in WinDNMR (Figure 21). ${ }^{[7 \mathrm{~d}]}$ The spectra and line shape analysis are shown in Figure 15.

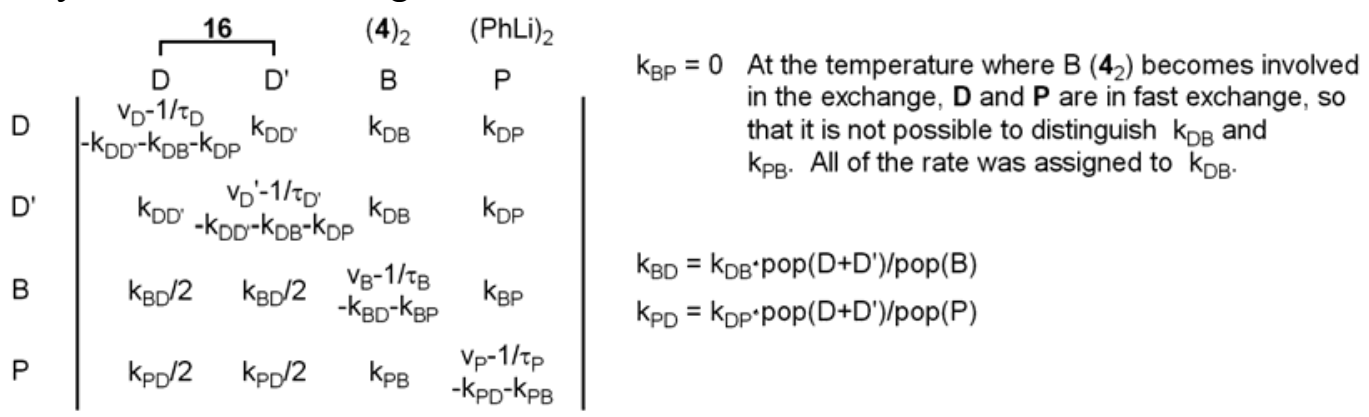

Figure 21. Exchange matrix for the exchange of mixed dimer $16\left(\mathbf{D}, \mathbf{D}^{\prime}\right)$ with $(\mathrm{PhLi})_{2}(\mathbf{P})$ and $(4)_{2} \bullet(B)$. 
This sample was diluted by factor of four: $1.0 \mathrm{~mL}$ of the solution was diluted with ether $(1.2 \mathrm{~mL})$ and THF $(1.8 \mathrm{~mL})$ in a second dried and $\mathrm{N}_{2}$-flushed $10 \mathrm{~mm}$ NMR tube to give a clear, pale yellow $0.05 \mathrm{M}$ solution. A second variable temperature experiment was monitored by ${ }^{13} \mathrm{C}$ and ${ }^{7} \mathrm{Li}$ NMR spectroscopy with spectra acquired at $-126,-116,-105,-91,-87,-81,-67,-60,-57,-$ $50,-46,-32,-26,-21,-15,-6$, and $5{ }^{\circ} \mathrm{C}$. The spectra and results of the line shape analysis are shown in Figure 16.

Variable-temperature iodine "ate" complex ${ }^{13} \mathrm{C}$ NMR experiment on 4 and 17. A VT experiment was conducted on the $0.13 \mathrm{M}$ sample used prior for the ${ }^{13} \mathrm{C} \mathrm{NMR}$ variabletemperature experiment. $N$-(ortho-Iodobenzyl)pyrrolidine (17, $145 \mu \mathrm{L}, 0.768 \mathrm{mmol}, 2.0$ equiv) was added to give a $0.13 \mathrm{M}$ solution in aryllithium reagent and $0.26 \mathrm{M}$ solution in aryl iodide. The variable temperature experiment was monitored by ${ }^{13} \mathrm{C}$ NMR spectroscopy with spectra acquired at the following probe temperatures: $-123,-75,-39$ and $-2{ }^{\circ} \mathrm{C}$. Above $-2{ }^{\circ} \mathrm{C}$, the sample began to decompose. Spectra are shown in Figure 18.

NMR experiment on ortho-[(pyrrolidinomethyl)dimethylsilyl]phenyllithium (11). A pure sample of $\mathbf{1 1}$ was prepared by the general procedure for the crystallization from ether and purification of aryllithium reagents for NMR. (ortho-Trimethylstannylphenyl)(pyrrolidinomethyl)dimethylsilane (203 $\mathrm{mg}, 0.530 \mathrm{mmol})$ and $1.90 \mathrm{M} n$-BuLi in hexane $(0.30 \mathrm{~mL}$, $0.56 \mathrm{mmol}, 1.06$ equiv) were added to a dried and $\mathrm{N}_{2}$-flushed $10 \mathrm{~mm}$ NMR tube. The aryllithium crystals were dissolved in THF $(1.8 \mathrm{~mL})$ and ether $(1.2 \mathrm{~mL})$ to give a clear, yellow $0.13 \mathrm{M}$ solution. ${ }^{13} \mathrm{C}$, ${ }^{6} \mathrm{Li}$, and ${ }^{7} \mathrm{Li}$ NMR spectra were taken (see Figure 19 ).

Single crystal X-ray structure of ortho-(pyrrolidinomethyl)phenyllithium B-type dimer. A sample of $\mathrm{Et}^{6} \mathrm{Li}(36.0 \mathrm{mg}, 1.0 \mathrm{mmol})$ was placed in an $\mathrm{N}_{2}$ purged $10 \mathrm{~mL}$ Schlenk flask. The flask was cooled to $-78{ }^{\circ} \mathrm{C}$, and ether $(3 \mathrm{~mL})$ and $6(270 \mu \mathrm{L} 0.95 \mathrm{mmol})$ were added. The flask was warmed briefly to dissolve the $\mathrm{Et}^{6} \mathrm{Li}$ and THF $(0.8 \mathrm{~mL})$ was added. Within $24 \mathrm{~h}$ a few large transparent crystals of $\mathbf{4}$ were present on the bottom of the flask. The crystals were submitted in this form (covered with the solution) for X-ray analysis. The structure is shown in Figure11.

A colorless prism-shaped crystal of dimensions $0.52 \times 0.45 \times 0.44 \mathrm{~mm}$ was selected for structural analysis. Intensity data for this compound were collected using a Bruker SMART ccd area detector ${ }^{[25]}$ mounted on a Bruker P4 goniometer using graphite-monochromated Mo Ka radiation $(1=0.71073 \AA)$. The sample was cooled to $133(2) \mathrm{K}$. The intensity data, which nominally covered one and a half hemispheres of reciprocal space, were measured as a series of oscillation frames each of $0.4^{\circ}$ for $30 \mathrm{sec} /$ frame. The detector was operated in 512 x 512 mode and was positioned $5.00 \mathrm{~cm}$ from the sample. Coverage of unique data was $97.6 \%$ complete to 25.00 degrees in q. Cell parameters were determined from a non-linear least squares fit of 5484 peaks in the range $2.35<\mathrm{q}<28.92^{\circ}$. The first 50 frames were repeated at the end of data collection and yielded 97 peaks showing a variation of $-0.04 \%$ during the data collection. A total of 9467 data were measured in the range $2.36<\mathrm{q}<28.92^{\circ}$. The data were corrected for absorption by the empirical method ${ }^{[26]}$ giving minimum and maximum transmission factors of 0.9659 and 0.9710 . The data were merged to form a set of 3373 independent data with $\mathrm{R}$ (int) $=0.0424$. 
The triclinic space group P-1 was determined by statistical tests and verified by subsequent refinement. The structure was solved by direct methods and refined by full-matrix least-squares methods on $F^{2}{ }^{\left[{ }^{[2]}\right.}$ Hydrogen atom positions were initially determined by geometry and were refined using a riding model. Non-hydrogen atoms were refined with anisotropic displacement parameters. A total of 163 parameters were refined against 3373 data to give $\mathrm{wR}\left(F^{2}\right)=0.1552$ and $\mathrm{S}=1.043$ for weights of $\mathrm{w}=1 /\left[\mathrm{s}^{2}\left(F^{2}\right)+(0.0950 \mathrm{P})^{2}+0.0450 \mathrm{P}\right]$, where $\mathrm{P}=\left[F_{\mathrm{O}}{ }^{2}+2 F_{\mathrm{C}}{ }^{2}\right] /$ 3. The final $\mathrm{R}(F)$ was 0.0517 for the 2502 observed, $[F>4 \mathrm{~s}(F)]$, data. The largest shift/s.u. was 0.000 in the final refinement cycle. The final difference map had maxima and minima of 0.350 and $-0.313 \mathrm{e} / \AA^{3}$, respectively.

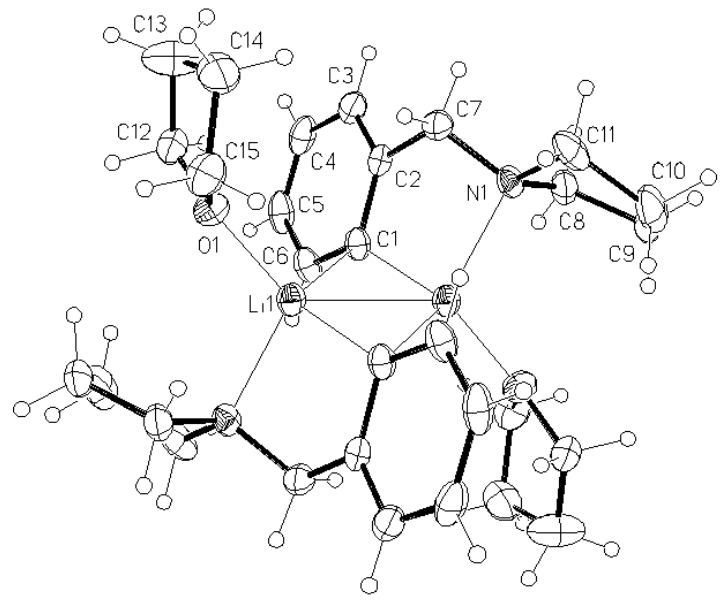

Table 3. Crystal data and structure refinement for $\mathbf{4}$

\begin{tabular}{lll}
\hline Identification code & 00083 & \\
Empirical formula & $2 \mathrm{Li}+2\left(\mathrm{C}_{4} \mathrm{H}_{8} \mathrm{O}\right) 2\left(\mathrm{C}_{11} \mathrm{H}_{14} \mathrm{~N}\right)-\mathrm{C}_{30} \mathrm{H}_{44} \mathrm{Li}_{2} \mathrm{~N}_{2} \mathrm{O}_{2}$ \\
Formula weight & 478.55 & \\
Crystal system & Triclinic & \\
Space group & $\mathrm{P}-1$ & $\mathrm{\alpha}=118.396(2)^{\circ}$ \\
Unit cell dimensions & $\mathrm{a}=8.4974(13) \AA$ & $\beta=99.319(3)^{\circ}$ \\
& $\mathrm{b}=9.9255(15) \AA$ & \\
& $\mathrm{c}=10.2154(15) \AA$ & $\mathrm{V}=100.175(2)^{\circ}$ \\
Volume & $715.27(19) \AA 3$ & \\
$Z$ & 1 & \\
Density (calculated) & $1.111 \mathrm{Mg} / \mathrm{m} 3$ & \\
Wavelength & $0.71073 \AA$ & \\
Temperature & $133(2) \mathrm{K}$ & \\
F(000) & 260 & \\
Absorption coefficient & $0.067 \mathrm{~mm}-1$ & \\
Absorption correction & Empirical & \\
Max. and min. transmission & 0.9710 and 0.9659 & \\
Theta range for data collection & 2.36 to $28.92^{\circ}$. & \\
Reflections collected & 9467 & \\
\hline
\end{tabular}


Table 3. Continued

\begin{tabular}{ll}
\hline Independent reflections & $3373[\mathrm{R}($ int $)=0.0424]$ \\
Data / restraints / parameters & $3373 / 0 / 163$ \\
$\mathrm{wR}\left(F^{2}\right.$ all data $)$ & $\mathrm{wR}=0.1552$ \\
$\mathrm{R}(F$ obsd data $)$ & $\mathrm{R}=0.0517$ \\
Goodness-of-fit on $F^{2}$ & 1.043 \\
Observed data $[\mathrm{I}>2 \mathrm{~s}(\mathrm{I})]$ & 2502 \\
Largest and mean shift $/$ s.u. & 0.000 and 0.000 \\
Largest diff. peak and hole & 0.350 and $-0.313 \mathrm{e} / \AA^{3}$ \\
\hline
\end{tabular}

Table 4. Atomic coordinates and equivalent isotropic displacement parameters for 4. U(eq) is defined as one third of the trace of the orthogonalized $U_{i j}$ tensor

\begin{tabular}{lllll}
\hline & $\mathrm{x}$ & $\mathrm{y}$ & $\mathrm{z}$ & $\mathrm{U}(\mathrm{eq})$ \\
\hline $\mathrm{Li}(1)$ & $0.4103(3)$ & $0.5619(3)$ & $0.4556(3)$ & $0.0284(3)$ \\
$\mathrm{O}(1)$ & $0.32294(12)$ & $0.73685(11)$ & $0.56694(11)$ & $0.0224(3)$ \\
$\mathrm{N}(1)$ & $0.71593(13)$ & $0.56269(12)$ & $0.78381(12)$ & $0.0220(3)$ \\
$\mathrm{C}(1)$ & $0.68501(15)$ & $0.66357(15)$ & $0.55699(15)$ & $0.0216(3)$ \\
$\mathrm{C}(2)$ & $0.75146(15)$ & $0.77410(15)$ & $0.71835(15)$ & $0.0272(3)$ \\
$\mathrm{C}(3)$ & $0.85448(16)$ & $0.92894(15)$ & $0.78040(17)$ & $0.0326(4)$ \\
$\mathrm{C}(4)$ & $0.89509(17)$ & $0.98178(16)$ & $0.68316(19)$ & $0.0325(4)$ \\
$\mathrm{C}(5)$ & $0.83588(17)$ & $0.87821(18)$ & $0.52502(19)$ & $0.0271(3)$ \\
$\mathrm{C}(6)$ & $0.73448(16)$ & $0.72324(17)$ & $0.46522(17)$ & $0.0252(3)$ \\
$\mathrm{C}(7)$ & $0.70547(17)$ & $0.72402(15)$ & $0.82925(16)$ & $0.0281(3)$ \\
$\mathrm{C}(8)$ & $0.88744(17)$ & $0.55253(16)$ & $0.79634(17)$ & $0.0376(4)$ \\
$\mathrm{C}(9)$ & $0.8795(2)$ & $0.39512(18)$ & $0.79177(19)$ & $0.0453(4)$ \\
$\mathrm{C}(10)$ & $0.7221(2)$ & $0.3604(2)$ & $0.8396(2)$ & $0.0341(4)$ \\
$\mathrm{C}(11)$ & $0.66382(19)$ & $0.50879(18)$ & $0.88507(17)$ & $0.0318(3)$ \\
$\mathrm{C}(12)$ & $0.40147(19)$ & $0.90482(16)$ & $0.63173(17)$ & $0.0584(5)$ \\
$\mathrm{C}(13)$ & $0.3708(3)$ & $0.9922(2)$ & $0.7874(2)$ & $0.0434(4)$ \\
$\mathrm{C}(14)$ & $0.2735(2)$ & $0.8626(2)$ & $0.80733(19)$ & $0.0361(4)$ \\
$\mathrm{C}(15)$ & $0.19960(18)$ & $0.72368(19)$ & $0.64404(19)$ & $0.0229(5)$ \\
\hline
\end{tabular}


Table 5. Bond lengths $[\AA]$ for 4

\begin{tabular}{lllll}
\cline { 1 - 1 } $\operatorname{Li}(1)-\mathrm{O}(1)$ & $1.926(2)$ & & $\mathrm{Li}(1)-\mathrm{C}(1)$ & $2.220(2)$ \\
$\mathrm{Li}(1)-\mathrm{N}(1) \# 1$ & $2.114(2)$ & & $\mathrm{Li}(1)-\mathrm{Li}(1) \# 1$ & $2.435(4)$ \\
$\mathrm{Li}(1)-\mathrm{C}(1) \# 1$ & $2.175(2)$ & & $\mathrm{O}(1)-\mathrm{C}(15)$ & $1.4328(16)$ \\
$\mathrm{O}(1)-\mathrm{C}(12)$ & $1.4413(17)$ & & $\mathrm{C}(3)-\mathrm{C}(4)$ & $1.387(2)$ \\
$\mathrm{N}(1)-\mathrm{C}(11)$ & $1.4640(17)$ & & $\mathrm{C}(4)-\mathrm{C}(5)$ & $1.376(2)$ \\
$\mathrm{N}(1)-\mathrm{C}(7)$ & $1.4644(16)$ & & $\mathrm{C}(5)-\mathrm{C}(6)$ & $1.3961(19)$ \\
$\mathrm{N}(1)-\mathrm{C}(8)$ & $1.4677(17)$ & & $\mathrm{C}(8)-\mathrm{C}(9)$ & $1.5298(19)$ \\
$\mathrm{N}(1)-\mathrm{L}(1) \# 1$ & $2.114(3)$ & & $\mathrm{C}(9)-\mathrm{C}(10)$ & $1.535(2)$ \\
$\mathrm{C}(1)-\mathrm{Li}(1) \# 1$ & $2.175(2)$ & & $\mathrm{C}(10)-\mathrm{C}(11)$ & $1.521(2)$ \\
$\mathrm{C}(1)-\mathrm{C}(6)$ & $1.4051(17)$ & & $\mathrm{C}(12)-\mathrm{C}(13)$ & $1.500(2)$ \\
$\mathrm{C}(1)-\mathrm{C}(2)$ & $1.4139(18)$ & & $\mathrm{C}(13)-\mathrm{C}(14)$ & $1.520(3)$ \\
$\mathrm{C}(2)-\mathrm{C}(3)$ & $1.3959(18)$ & & $\mathrm{C}(14)-\mathrm{C}(15)$ & $1.498(2)$ \\
$\mathrm{C}(2)-\mathrm{C}(7)$ & $1.5145(18)$ & & & \\
\cline { 1 - 2 } & & &
\end{tabular}

Table 6. Bond angles $\left[^{\circ}\right]$ for 4

\begin{tabular}{|c|c|c|c|}
\hline $\mathrm{O}(1)-\mathrm{Li}(1)-\mathrm{N}(1) \# 1$ & $109.71(11)$ & $\mathrm{C}(2)-\mathrm{C}(1)-\mathrm{Li}(1) \# 1$ & $103.06(10)$ \\
\hline $\mathrm{O}(1)-\operatorname{Li}(1)-\mathrm{C}(1) \# 1$ & $118.92(11)$ & $C(6)-C(1)-\operatorname{Li}(1)$ & $103.55(10)$ \\
\hline $\mathrm{N}(1) \# 1-\mathrm{Li}(1)-\mathrm{C}(1) \# 1$ & $85.91(9)$ & $C(2)-C(1)-\operatorname{Li}(1)$ & $119.17(10)$ \\
\hline $\mathrm{O}(1)-\mathrm{Li}(1)-\mathrm{C}(1)$ & 104.81(11) & $\operatorname{Li}(1) \# 1-C(1)-\operatorname{Li}(1)$ & $67.27(10)$ \\
\hline $\mathrm{N}(1) \# 1-\mathrm{Li}(1)-\mathrm{C}(1)$ & $125.07(10)$ & $C(3)-C(2)-C(1)$ & $123.01(12)$ \\
\hline $\mathrm{C}(1) \# 1-\operatorname{Li}(1)-\mathrm{C}(1)$ & $112.73(10)$ & $\mathrm{C}(3)-\mathrm{C}(2)-\mathrm{C}(7)$ & $118.34(12)$ \\
\hline $\mathrm{O}(1)-\operatorname{Li}(1)-\operatorname{Li}(1) \# 1$ & $131.68(16)$ & $\mathrm{C}(1)-\mathrm{C}(2)-\mathrm{C}(7)$ & $118.63(11)$ \\
\hline $\mathrm{N}(1) \# 1-\operatorname{Li}(1)-\operatorname{Li}(1) \# 1$ & $117.39(14)$ & $C(4)-C(3)-C(2)$ & $120.31(13)$ \\
\hline C(1)\#1-Li(1)-Li(1)\#1 & $57.25(9)$ & $C(5)-C(4)-C(3)$ & $119.09(12)$ \\
\hline C(1)-Li(1)-Li(1)\#1 & $55.48(9)$ & $C(4)-C(5)-C(6)$ & 119.73(13) \\
\hline$C(15)-O(1)-C(12)$ & $107.71(10)$ & $C(5)-C(6)-C(1)$ & $124.08(14)$ \\
\hline $\mathrm{C}(15)-\mathrm{O}(1)-\mathrm{Li}(1)$ & 121.91(11) & $\mathrm{N}(1)-\mathrm{C}(7)-\mathrm{C}(2)$ & $112.25(10)$ \\
\hline $\mathrm{C}(12)-\mathrm{O}(1)-\mathrm{Li}(1)$ & $127.10(10)$ & $\mathrm{N}(1)-\mathrm{C}(8)-\mathrm{C}(9)$ & $104.43(11)$ \\
\hline $\mathrm{C}(11)-\mathrm{N}(1)-\mathrm{C}(7)$ & $113.12(10)$ & $C(8)-C(9)-C(10)$ & $104.39(12)$ \\
\hline $\mathrm{C}(11)-\mathrm{N}(1)-\mathrm{C}(8)$ & $102.96(11)$ & $\mathrm{C}(11)-\mathrm{C}(10)-\mathrm{C}(9)$ & $104.22(12)$ \\
\hline $\mathrm{C}(7)-\mathrm{N}(1)-\mathrm{C}(8)$ & $112.67(10)$ & $\mathrm{N}(1)-\mathrm{C}(11)-\mathrm{C}(10)$ & $103.24(12)$ \\
\hline $\mathrm{C}(11)-\mathrm{N}(1)-\mathrm{Li}(1) \# 1$ & $121.17(10)$ & $\mathrm{O}(1)-\mathrm{C}(12)-\mathrm{C}(13)$ & $106.71(13)$ \\
\hline $\mathrm{C}(7)-\mathrm{N}(1)-\mathrm{Li}(1) \# 1$ & $100.33(10)$ & $C(12)-C(13)-C(14)$ & $105.28(14)$ \\
\hline $\mathrm{C}(8)-\mathrm{N}(1)-\mathrm{Li}(1) \# 1$ & $106.77(10)$ & $C(15)-C(14)-C(13)$ & $103.19(13)$ \\
\hline$C(6)-C(1)-\operatorname{Li}(1) \# 1$ & $140.83(11)$ & $\mathrm{O}(1)-\mathrm{C}(15)-\mathrm{C}(14)$ & $104.43(12)$ \\
\hline
\end{tabular}

Symmetry transformations used to generate equivalent atoms: $\# 1-\mathrm{x}+1,-\mathrm{y}+1,-\mathrm{z}^{+} 1$. 
Table 7. Torsion angles $\left[^{\circ}\right]$ for 4

\begin{tabular}{|c|c|c|c|}
\hline $\mathrm{N}(1) \# 1-\mathrm{Li}(1)-\mathrm{O}(1)-\mathrm{C}(15)$ & $97.64(14)$ & $C(2)-C(3)-C(4)-C(5)$ & $-1.61(19)$ \\
\hline $\mathrm{C}(1) \# 1-\mathrm{Li}(1)-\mathrm{O}(1)-\mathrm{C}(15)$ & $1.25(19)$ & $C(3)-C(4)-C(5)-C(6)$ & $0.9(2)$ \\
\hline $\mathrm{C}(1)-\mathrm{Li}(1)-\mathrm{O}(1)-\mathrm{C}(15)$ & $-125.82(12)$ & $C(4)-C(5)-C(6)-C(1)$ & $0.8(2)$ \\
\hline $\mathrm{Li}(1) \# 1-\mathrm{Li}(1)-\mathrm{O}(1)-\mathrm{C}(15)$ & $-69.1(2)$ & $C(2)-C(1)-C(6)-C(5)$ & $-1.71(18)$ \\
\hline $\mathrm{N}(1) \# 1-\mathrm{Li}(1)-\mathrm{O}(1)-\mathrm{C}(12)$ & $-105.39(14)$ & $\mathrm{Li}(1) \# 1-\mathrm{C}(1)-\mathrm{C}(6)-\mathrm{C}(5)$ & $-160.36(14)$ \\
\hline $\mathrm{C}(1) \# 1-\mathrm{Li}(1)-\mathrm{O}(1)-\mathrm{C}(12)$ & $158.22(12)$ & $\mathrm{Li}(1)-\mathrm{C}(1)-\mathrm{C}(6)-\mathrm{C}(5)$ & $129.12(13)$ \\
\hline $\mathrm{C}(1)-\mathrm{Li}(1)-\mathrm{O}(1)-\mathrm{C}(12)$ & $31.16(16)$ & $\mathrm{C}(11)-\mathrm{N}(1)-\mathrm{C}(7)-\mathrm{C}(2)$ & $-177.09(11)$ \\
\hline Li(1)\#1-Li(1)-O(1)-C(12) & $87.8(2)$ & $\mathrm{C}(8)-\mathrm{N}(1)-\mathrm{C}(7)-\mathrm{C}(2)$ & $66.64(14)$ \\
\hline $\mathrm{O}(1)-\mathrm{Li}(1)-\mathrm{C}(1)-\mathrm{C}(6)$ & $-89.44(12)$ & $\mathrm{Li}(1) \# 1-\mathrm{N}(1)-\mathrm{C}(7)-\mathrm{C}(2)$ & $-46.56(12)$ \\
\hline $\mathrm{N}(1) \# 1-\mathrm{Li}(1)-\mathrm{C}(1)-\mathrm{C}(6)$ & $38.28(15)$ & $\mathrm{C}(3)-\mathrm{C}(2)-\mathrm{C}(7)-\mathrm{N}(1)$ & $-136.50(12)$ \\
\hline$C(1) \# 1-\operatorname{Li}(1)-C(1)-C(6)$ & $139.79(12)$ & $\mathrm{C}(1)-\mathrm{C}(2)-\mathrm{C}(7)-\mathrm{N}(1)$ & $45.03(15)$ \\
\hline Li(1)\#1-Li(1)-C(1)-C(6) & $139.79(12)$ & $\mathrm{C}(11)-\mathrm{N}(1)-\mathrm{C}(8)-\mathrm{C}(9)$ & $41.68(14)$ \\
\hline $\mathrm{O}(1)-\mathrm{Li}(1)-\mathrm{C}(1)-\mathrm{C}(2)$ & $38.09(15)$ & $\mathrm{C}(7)-\mathrm{N}(1)-\mathrm{C}(8)-\mathrm{C}(9)$ & $163.87(11)$ \\
\hline $\mathrm{N}(1) \# 1-\mathrm{Li}(1)-\mathrm{C}(1)-\mathrm{C}(2)$ & $165.81(11)$ & $\mathrm{Li}(1) \# 1-\mathrm{N}(1)-\mathrm{C}(8)-\mathrm{C}(9)$ & $-86.93(12)$ \\
\hline$C(1) \# 1-\mathrm{Li}(1)-\mathrm{C}(1)-\mathrm{C}(2)$ & $-92.68(13)$ & $\mathrm{N}(1)-\mathrm{C}(8)-\mathrm{C}(9)-\mathrm{C}(10)$ & $-21.23(15)$ \\
\hline Li(1)\#1-Li(1)-C(1)-C(2) & $-92.68(13)$ & $C(8)-C(9)-C(10)-C(11)$ & $-6.16(16)$ \\
\hline $\mathrm{O}(1)-\mathrm{Li}(1)-\mathrm{C}(1)-\mathrm{Li}(1) \# 1$ & $130.77(15)$ & $C(7)-N(1)-C(11)-C(10)$ & $-167.52(12)$ \\
\hline $\mathrm{N}(1) \# 1-\mathrm{Li}(1)-\mathrm{C}(1)-\mathrm{Li}(1) \# 1$ & $-101.51(15)$ & $\mathrm{C}(8)-\mathrm{N}(1)-\mathrm{C}(11)-\mathrm{C}(10)$ & $-45.63(13)$ \\
\hline $\mathrm{C}(1) \# 1-\mathrm{Li}(1)-\mathrm{C}(1)-\mathrm{Li}(1) \# 1$ & 0.0 & Li(1)\#1-N(1)-C(11)-C(10) & $73.39(15)$ \\
\hline$C(6)-C(1)-C(2)-C(3)$ & $0.97(17)$ & $\mathrm{C}(9)-\mathrm{C}(10)-\mathrm{C}(11)-\mathrm{N}(1)$ & $31.47(15)$ \\
\hline $\mathrm{Li}(1) \# 1-\mathrm{C}(1)-\mathrm{C}(2)-\mathrm{C}(3)$ & $167.32(11)$ & $\mathrm{C}(15)-\mathrm{O}(1)-\mathrm{C}(12)-\mathrm{C}(13)$ & $20.94(17)$ \\
\hline $\mathrm{Li}(1)-\mathrm{C}(1)-\mathrm{C}(2)-\mathrm{C}(3)$ & $-121.64(13)$ & $\mathrm{Li}(1)-\mathrm{O}(1)-\mathrm{C}(12)-\mathrm{C}(13)$ & $-138.67(15)$ \\
\hline$C(6)-C(1)-C(2)-C(7)$ & $179.36(10)$ & $\mathrm{O}(1)-\mathrm{C}(12)-\mathrm{C}(13)-\mathrm{C}(14)$ & $1.23(19)$ \\
\hline $\mathrm{Li}(1) \# 1-\mathrm{C}(1)-\mathrm{C}(2)-\mathrm{C}(7)$ & $-14.29(13)$ & $C(12)-C(13)-C(14)-C(15)$ & $-21.47(19)$ \\
\hline $\mathrm{Li}(1)-\mathrm{C}(1)-\mathrm{C}(2)-\mathrm{C}(7)$ & $56.76(15)$ & $\mathrm{C}(12)-\mathrm{O}(1)-\mathrm{C}(15)-\mathrm{C}(14)$ & $-34.91(15)$ \\
\hline$C(1)-C(2)-C(3)-C(4)$ & $0.64(19)$ & $\mathrm{Li}(1)-\mathrm{O}(1)-\mathrm{C}(15)-\mathrm{C}(14)$ & $125.97(13)$ \\
\hline$C(7)-C(2)-C(3)-C(4)$ & $-177.76(11)$ & $\mathrm{C}(13)-\mathrm{C}(14)-\mathrm{C}(15)-\mathrm{O}(1)$ & $34.29(17)$ \\
\hline
\end{tabular}

Symmetry transformations used to generate equivalent atoms: $\# 1-\mathrm{x}+1,-\mathrm{y}+1,-\mathrm{z}+1$.

\section{Acknowledgments}

The authors thank the National Science Foundation (grants CHE-0074657 and CHE-9703589) and the University of Wisconsin for support of this research. The NSF also provided instrumentation grants for purchase of the Brucker Avance NMR spectrometer (CHE-9709065) and the diffractometer and computers used in X-ray crystal structure determination (CHE9709005). We thank Michael A. Kozee for determining the X-ray structure. 


\section{Supplementary Information Available}

Crystallographic image for compound $(4)_{2} \bullet(T H F)_{2}$ is available on page 130 .

\section{References}

1. (a) Jones, F. N.; Zinn, M. F.; Hauser, C. R. J. Org. Chem. 1963, 28, 663. (b) Klein, K. P.; Hauser, C. R. J. Org. Chem. 1967, 32, 1479.

2. (a) Gschwend, H. W.; Rodriguez, H. R. Org. React. 1979, 26, 1. (b) Beak, P.; Snieckus, V. Acc. Chem. Res. 1982, 15, 306. (c) Beak, P.; Meyers, A. I. Acc. Chem. Res. 1986, 19, 356. (d) Klumpp, G. W. Recl. Trav. Chim. Pays-Bas 1986, 105, 1. (e) Snieckus, V. Chem. Rev. 1990, 90, 879.

3. Chauder, B.; Larkin, A.; Snieckus, V., Org. Lett. 2002, 4, 815.

4. (a) Jastrzebski, J. T. B. H.; van Koten, G.; Konijn, M.; Stam, C. H. J. Am. Chem. Soc. 1982, 104, 5490. (b) Wehman, E.; Jastrzebski, J. T. B. H.; Ernsting, J.-M.; Grove, D. M.; van Koten, G. J. Organomet. Chem. 1988, 353, 145. (c) Rietveld, M. H. P.; Wehman-Ooyevaar, I. C. M.; Kapteijn, G. M.; Grove, D. M.; Smeets, W. J. J.; Kooijman, H.; Spek, A. L.; van Koten, G. Organometallics 1994, 13, 3782. (d) Jastrzebski, J. T. B. H.; van Koten, G.; Goubitz, K.; Arlen, C.; Pfeffer, M. J. Organomet. Chem. 1983, 246, C75. (e) WehmanOoyevaar, I. C. M.; Kapteijn, G. M.; Grove, D. M.; Spek, A. L.; van Koten, G. J. Organomet. Chem. 1993, 452, C1. (f) van Koten, G.; Noltes, J. G. J. Am. Chem. Soc. 1976, 98, 5393.

5. Hope, H.; Power, P. P. J. Am. Chem. Soc. 1983, 105, 5320.

6. Oakes, F. T.; Sebastian, J. F. J. Organomet. Chem. 1978, 159, 363.

7. (a) Reich, H. J.; Gudmundsson, B. Ö. J. Am. Chem. Soc. 1996, 118, 6074. (b) Reich, H. J; Goldenberg, W. S.; Gudmundsson, B. Ö.; Sanders, A. W.; Kulicke, K. J.; Simon, K.; Guzei, I. A. J. Am. Chem. Soc. 2001, 123, 8067. (c) Reich, H. J; Goldenberg, W. S.; Sanders, A. W.; Jantzi, K. L.; Tzschucke, C. C. J. Am. Chem. Soc. 2003, 125, 3509. (d) Reich, H. J.; Green, D. P.; Medina, M. A.; Goldenberg, W. S.; Gudmundsson, B. Ö.; Dykstra, R. R.; Phillips, N. H. J. Am. Chem. Soc. 1998, 120, 7201. (e) Line shape simulations were performed with the program WINDNMR. Reich, H. J. J. Chem. Ed. Software, 1996, 3D, 2; for an updated version (WINDNMR-Pro) see: http://www.chem.wisc.edu/areas/reich/plt/windnmr.htm. (f) Sikorski, W. H.; Sanders, A. W.; Reich, H. J. Magn. Reson. Chem. 1998, 36, S118. (g) Reich, H. J.; Borst, J. P.; Dykstra, R. R.; Green, D. P. J. Am. Chem. Soc. 1993, 115, 8728. (h) Reich, H. J.; Phillips, N. H.; Reich, I. L. J. Am. Chem. Soc. 1985, 107, 4101. (i) Reich, H. J.; Green, D. P.; Phillips, N. H. J. Am. Chem. Soc. 1989, 111, 3444. (j) Reich, H. J.; Green, D. P. J. Am. Chem. Soc. 1989, 111, 8729. (k) Reich, H. J.; Phillips, N. H. J. Am. Chem. Soc. 1986, 108, 2102. 
8. (a) Bauer, W.; Winchester, W. R.; Schleyer, P. v. R. Organometallics 1987, 6, 2371. (b) Harder, S.; Boersma, J.; Brandsma, L.; Kanters, J. A.; Bauer, W.; Schleyer, P.v.R. Organometallics 1989, 8, 1696.

9. (a) Seebach, D.; Hässig, R.; Gabriel, J. Helv. Chim. Acta 1983, 66, 308. (b) Bauer, W.; Seebach, D. Helv. Chim. Acta 1984, 67, 1972.

10. Eppers, O.; Günther, H. Helv. Chim. Acta 1992, 75, 2553.

11. (a) Collum, D. B. Acc. Chem. Res. 1992, 25, 448. (b) Lucht, B. L.; Bernstein, M. P.; Remenar, J. F.; Collum, D. B. J. Am. Chem. Soc. 1996, 118, 10707. (c) Lucht, B. L.; Collum, D. B. J. Am. Chem. Soc. 1995, 117, 9863. (d) Hoffmann D.; Collum D. B. J. Am. Chem. Soc. 1998, $120,5810$.

12. (a) Arnett, E. M.; Fisher, F. J.; Nichols, M. A.; Ribeiro, A. A. J. Am. Chem. Soc. 1990, 112, 801. (b) Kmínek, I.; Kašpar, M.; Tvekoval, J. Collect. Czech. Chem. Commun. 1981, 46, 1124 and 1132.

13. Hilmersson G.; Davidsson, Ö. J. Org. Chem. 1995, 60, 7660.

14. (a) Bevan, M. J., Ph. D. Thesis, University of Wisconsin: Madison, 2003. (b) Whipple, W. L., Ph. D. Thesis, University of Wisconsin: Madison, 1990.

15. Bailey, W. F.; Patricia, J. J. J. Organomet. Chem. 1988, 352, 1.

16. Newcomb, M.; Horner, J. H. Blanda, M. T. J. Am. Chem. Soc. 1987, 109, 7878.

17. Ochiai, M.; Iwaki, S.; Ukita, T.; Matsuura, Y.; Shiro, M.; Nagao; Y. J. Am. Chem. Soc. 1988, $110,4606$.

18. Weak interactions have been detected: Jurkschat, K.; Tzschach, A. J. Organomet. Chem. 1984, 272, C13.

19. Ruzicka, A.; Pejchal, V.; Holecek, J.; Lycka, A.; Jacob, K. Collect. Czech. Commun. 1998, 63, 977.

20. Aldrich Chemical Company Technical Information Bulletin AL-134.

21. Watson, S. C.; Eastham, J. F. J. Organomet. Chem. 1967, 9, 165.

22. Hutchins, R. O.; Markowitz, M. J. Org. Chem. 1981, 46, 3571.

23. Wilson, S. R.; Zucker, P. A.; Huang, R.-R. C.; Spector, A. J. Am. Chem. Soc. 1989, 111, 5936.

24. Murakami, M.; Hayashi, M.; Ito, Y. J. Org. Chem. 1992, 57, 793.

25. (a) Data Collection: SMART Software Reference Manual (1994). Bruker-AXS, 6300 Enterprise Dr., Madison, WI 53719-1173, USA. (b) Data Reduction: SAINT Software Reference Manual (1995). Bruker-AXS, 6300 Enterprise Dr., Madison, WI 53719-1173, USA.

26. Sheldrick, G. M., (1996). SADABS. Program for Empirical Absorption Correction of Area Detector Data. University of Göttingen, Germany.

27. (a) Sheldrick, G. M., (1994). SHELXTL Version 5 Reference Manual. Bruker-AXS, 6300 Enterprise Dr., Madison, WI 53719, USA. (b) International Tables for Crystallography, Vol C, Tables 6.1.1.4, 4.2.6.8, and 4.2.4.2, Kluwer: Boston, 1995. 